\title{
Momentum transport processes in the stratiform regions of mesoscale convective systems over the western Pacific warm pool
}

\author{
By DAVID B. MECHEM ${ }^{1 *}$, SHUYI S. CHEN ${ }^{2}$ and ROBERT A. HOUZE, Jr. $^{3}$ \\ ${ }^{1}$ Cooperative Institute for Mesoscale Meteorological Studies, University of Oklahoma, USA \\ ${ }^{2}$ Rosenstiel School of Marine and Atmospheric Sciences, University of Miami, USA \\ ${ }^{3}$ Department of Atmospheric Sciences, University of Washington, USA
}

(Received 16 September 2004; revised 29 September 2005)

\section{SUMMARY}

Momentum transport by the stratiform components of mesoscale convective systems (MCSs) during the Tropical Ocean-Global Atmosphere Coupled Ocean-Atmosphere Response Experiment in December 1992 is investigated using a cloud-resolving model. The mesoscale momentum transport by the stratiform regions of MCSs is examined in two distinct large-scale flow regimes associated with the intraseasonal oscillation over the western Pacific warm pool. Model simulations for 14 December 1992 characterize the 'westerly onset' period, which has relatively weak low-level westerlies with easterlies above. Simulations for 23-24 December represent the 'strong westerly' regime, when westerlies extend from the upper troposphere to the surface, with a jet 2-3 km above the surface. In the westerly onset simulation, the extensive stratiform region of a MCS contained a broad region of descent that transported easterly momentum associated with the mid-level easterly jet downward. Thus, the stratiform regions acted as a negative feedback to decrease the large-scale mean westerly momentum developing at low levels. In the strong westerly regime, the mesoscale downward air motion in the stratiform regions of large MCSs transported westerly momentum downward and thus acted as a positive feedback, strengthening the already strong westerly momentum at low levels. Momentum fluxes by the mesoscale stratiform region downdraughts are shown to have a systematic and measurable impact on the large-scale momentum budget.

KEYWORDS: Madden-Julian Oscillation Organized convection Up-scale feedback

\section{INTRODUCTION}

Deep convective cloud systems include 'mesoscale convective systems' or MCSs, which exhibit a dual structure consisting of a convective and a stratiform region (Zipser 1969, 1977; Houze 1982, 1989, 1997). This dual structure has contributed to the difficulty of evaluating the overall role of the MCS in momentum transports that affect the large-scale flow. Early studies of convective momentum transports (Houze 1973; Schneider and Lindzen 1976; Shapiro and Stevens 1980) computed only those associated with convective updraughts. Moncrieff $(1978,1981,1992)$ took a different approach by developing a series of MCS airflow models based on conservation of properties along streamlines. The Moncrieff streamline models take into account the shear as well as the thermodynamic stratification of the environment, and show the general structure and momentum transporting characteristics of the mesoscale circulation of an ideal, steady-state MCS. The idealized MCS circulation appears to feed back constructively to the momentum field of certain large-scale circulations, especially the Madden-Julian Oscillation (MJO, Madden and Julian 1971, 1972), for which the idealized MCS circulation exhibits a scale-independent self similarity (Moncrieff 2004). To first approximation, the idealized layered flows depicted by the theory of Moncrieff resemble the mesoscale circulations in real observed storms (Kingsmill and Houze 1999; Bryan and Fritsch 2000) and storms represented by cloud-resolving models (e.g. Mechem et al. 2002). However, real MCSs may occur in environments with complex shear profiles, and they are usually three dimensional (3D) and non-steady. The Moncrieff models are steady in a reference frame moving along with travelling systems. They represent, in a

* Corresponding author: Cooperative Institute for Mesoscale Meteorological Studies, University of Oklahoma, 100 E. Boyd, Room 1110, Norman, OK 73019-1011, USA. e-mail: dmechem@ou.edu

(c) Royal Meteorological Society, 2006. 
simple way, some aspects of three-dimensionality such as overturning in the plane transverse to the direction of travel (Moncrieff and Miller 1976). But for reasons of mathematical tractability, the 2D idealizations have been explored the most thoroughly. The idealized models represent the broad dynamical morphology of the travelling convective systems, not their detailed structure. It is important to evaluate the idealized models against real-world systems for several reasons. In particular, the sizes and shapes of the stratiform regions of real MCSs vary considerably, and the properties of the MCS mesoscale circulations may vary in relation to these structural variations. Yang and Houze (1996) subdivided the momentum budget of a MCS into its stratiform and convective components, and found that the momentum budget over the stratiform region of a $2 \mathrm{D}$ simulated squall line can be considerably different from that over the narrow convective zone, and that no particular forcing term in either region dominates how the entire MCS influences the large-scale momentum profile. The implication is that the overall momentum transport by a MCS depends on the actual dimensions of its convective and stratiform regions. In a 3D simulation of an asymmetric tropical western Pacific squall line that included a large region of stratiform precipitation, Trier et al. (1998) found a counter-gradient vertical transport of zonal momentum at mid-levels in the convective region but a more complicated behaviour over the stratiform region. They found that system-averaged accelerations were generally much smaller than the individual components of the forcing. Mapes and Wu (2001) calculated convective-scale eddy momentum tendencies from a 2D cloud-resolving model simulation of an 18-day period during the Tropical Ocean-Global Atmosphere Coupled Ocean-Atmosphere Response Experiment (TOGA COARE). They found that the convective momentum transport profile was largely out of phase with the zonal wind profile, causing local extrema in the momentum profile (i.e. jets) to descend. Their shorter (7 day) 2D and 3D simulations of convection from GATE (Global Atmospheric Research Programme (GARP) Atlantic Tropical Experiment) consistently showed similar descending mid-level jet structures. For none of these cases, however, did they pursue fully the contribution by stratiform regions of MCSs to the momentum fluxes.

The MCSs that occur over the west Pacific warm pool are some of the largest observed anywhere on earth (Nakazawa 1988; Mapes and Houze 1993; Chen et al. 1996). These large MCSs, sometimes called 'superclusters', have large stratiform regions and are thought to have a major impact on the momentum budget of the warm-pool region. Because of their large stratiform regions, the warm-pool MCSs are ideally suited for study of the stratiform region's contribution to momentum transports. Moncrieff and Klinker (1997) inferred from a general circulation model that the superclusters over the warm pool strongly affected the low-level wind field over the warm pool; however, they were unable to relate the momentum transport specifically to the convective or stratiform regions of the MCSs, owing to the coarse resolution of the model grid.

The convection over the warm pool was documented extensively in the TOGA COARE field campaign (Godfrey et al. 1998). Unique observations were obtained by several airborne and shipborne Doppler radars. The TOGA COARE dataset, therefore, constitutes an important test-bed for improving our understanding of the role of the large stratiform regions in redistributing environmental momentum. In this paper we examine MCSs in the TOGA COARE environment via simulations with a cloud-resolving model and in the light of TOGA COARE observations.

The large-scale circulation during TOGA COARE (November 1992 to February 1993) was dominated by the MJO, which is essentially an eastward-propagating version of the idealized equatorial Kelvin-Rossby (KR) wave complex described by Gill (1980). 

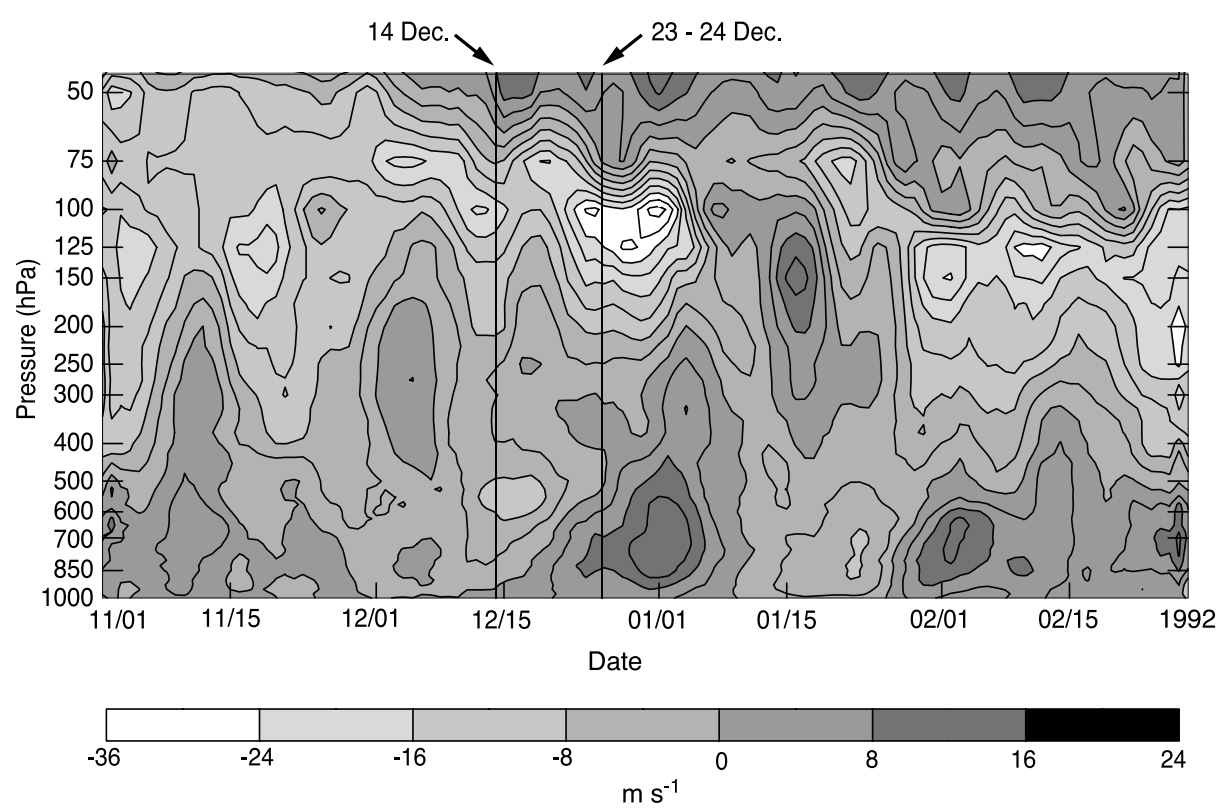

Figure 1. Time-height plot of the 5-day running mean of zonal wind from rawinsonde observations taken over the TOGA COARE (see text) Intensive Flux Array. Vertical lines denote the times of the westerly onset (positive values) and strong westerly periods simulated in this study. Dates are given in the form $\mathrm{mm} / \mathrm{dd}$. (Adapted from Chen et al. 1996.)

The combination of Kelvin and Rossby wave structures produces large-scale cyclonic gyres located on either side of a symmetric Kelvin mode. In the idealized Gill model the Kelvin mode is centred on the equator, but in reality the westerlies are often centred slightly off the equator. The complex moves generally eastward, and its structure evolves in time. Chen et al. (1996) and Houze et al. (2000) have described observed aspects of the Kelvin-Rossby wave structures that occurred in TOGA COARE. They found that the surface wind pattern in the KR wave structure had a strong westerly region between the large-scale cyclonic gyres, and a well-defined low-level westerly onset region located just ahead (or east) of the strongest westerly region. In TOGA COARE, the westerly winds appeared first at the surface in the westerly onset region, before the westerly wind reached its maximum above the planetary boundary layer (PBL) in the strong westerly region. This behaviour is evident at $850 \mathrm{hPa}$ in the beginning of January 1992 (Fig. 1). The most active and organized convection was observed in the westerly regime (see, e.g. Fig. 8(j) of Chen et al. (1996)) in contrast to the idealized Gill model, where heating (and by inference convection) is located in between the easterlies and westerlies associated with the MJO. The lack of vertical structure in the Gill model, specifically the lack of tilt with height, is a major drawback in correctly representing the KR wave structure. Furthermore, the lack of a realistic PBL in most of the Gill-type models inhibits momentum transport from the upper and middle troposphere to levels near the surface.

Houze et al. (2000) qualitatively analysed the MCSs occurring in the westerly onset and strong westerly regions by using Doppler radar data obtained on ships and aircraft during TOGA COARE. They examined several very large MCSs and found observational evidence that the mesoscale stratiform regions of the large MCSs were major contributors to the momentum transport, especially in the mid-to-lower 
troposphere. Furthermore, they showed that the structure and evolution of the convective systems were distinctly different in the westerly onset from those in the strong westerly regimes.

Houze et al. (2000) found evidence in the Doppler radar data collected during TOGA COARE that the stratiform regions of MCSs occurring in the westerly onset phase of the KR wave pattern transported easterly momentum downward (a negative feedback to the increasing large-scale westerly momentum), while during the strong westerly phase of the KR wave pattern the stratiform regions of MCSs transported westerly momentum downward (a positive feedback to the already strong westerlies at low levels). Analyses of rawinsonde and wind profiler data from TOGA COARE are consistent with this result, in showing that the net lower tropospheric momentum transport is down-gradient $60-65 \%$ of the time, except during the strong westerly phase where it is counter-gradient and helps to maintain the mean shear (Tung and Yanai 2002).

This study presents cloud-resolving model results that test the hypotheses of Houze et al. (2000) and identifies the mechanisms contributing to the momentum transport in the stratiform regions of MCSs in TOGA COARE. These results agree with, and give physical insight into, the conclusions of Houze et al. (2000) for both the westerly onset and strong westerly flow regimes. We show further how the convective and stratiform regions of the TOGA COARE MCSs work sometimes in concert and sometimes in opposition in the large-scale vertical redistribution of momentum, especially at low levels. We focus in particular on the zonal component of the large-scale flow and momentum transport by large MCSs, since the zonal component is most relevant to the establishment of the structure of the large-scale KR wave.

\section{NUMERICAL MODEL}

Details of the numerical model and experimental set-up are given in Mechem et al. (2002). Deep convection is simulated using the fully compressible, primitiveequation Advanced Regional Prediction System (ARPS) cloud model (Xue et al. 1995). The horizontal grid spacing is $2 \mathrm{~km}$, and the vertical grid spacing ranges from 200 $\mathrm{m}$ at the surface to $1000 \mathrm{~m}$ aloft, enabling the model to resolve the shallow tropical cold pools induced by convection over the western Pacific warm-pool region. The bulk microphysical parametrization employs the Lin et al. (1983) scheme, modified to represent better the microphysical behaviour in the stratiform region (Potter 1991; Yang and Houze 1995a,b). A turbulent kinetic energy scheme parametrizes subgridscale processes.

To capture MCS structure evolving from an environment containing mesoscale variability, we use the initial and boundary conditions from the output of a mesoscale model simulation performed with the fifth generation Penn State University/National Center for Atmospheric Research non-hydrostatic mesoscale model (MM5, Grell et al. 1994). The simulations were conducted using 25 vertical levels and a nested grid of two domains with horizontal grid spacing of 45 and $15 \mathrm{~km}$, respectively, for several consecutive days in mid-to-late December 1992 (Chen 1997). The MM5 inner domain had dimensions $\sim 2500 \mathrm{~km} \times 1500 \mathrm{~km}$ and included the TOGA COARE Intensive Flux Array (IFA, Godfrey et al. 1998). The Kain and Fritsch (1990) scheme parametrized subgrid-scale deep convection, and a simple bulk ice-phase parametrization for clouds was employed on the resolvable scale. European Centre for Medium-Range Weather Forecasts analysis fields, National Centers for Environmental Prediction sea surface 
temperature (SST) analyses, and TOGA COARE soundings supplied initial and boundary conditions for MM5. The MM5 simulations were able to produce large MCSs similar to those observed during TOGA COARE in satellite data. The ARPS model $(2 \mathrm{~km}$ horizontal grid spacing) simulations used a subset of the fine-mesh (15 km) MM5 simulations as initial and boundary conditions. The experimental configuration is the same as that in Mechem et al. (2002), except that the initial mid-level zonal momentum profile was modified in the 14 December case to examine the sensitivity of MCS organization to varying large-scale wind profiles. Readers are referred to Mechem et al. (2002) for more details of the multi-model approach.

This configuration we employ, in which ARPS boundary conditions are supplied from a previous MM5 simulation, is in effect a one-way nesting. A method similar to that used by Davies (1983) applies a forcing term to the right-hand side of the ARPS momentum and scalar equations over a narrow $(10 \mathrm{~km})$ zone along the lateral boundaries. The imposed boundary forcings are a combination of the large-scale flow and any response of the parametrized and resolved convection on the $15 \mathrm{~km}$ MM5 grid. This treatment of boundary conditions can be considered a physically consistent manner of treating the flow in and around a finite domain, in contrast to the radiation or periodic boundary conditions used in many previous studies on momentum transport. However, because of the one-way nesting methodology, the ARPS and MM5 momentum fields are not necessarily mutually consistent. Basically, ARPS responds to the initial and boundary conditions imposed by the MM5, but the MM5 has no way of responding to the MCSs explicitly generated by ARPS. In addition, transport terms evaluated near the boundary zones will likely contain contributions from both the MCS and boundary forcings. For these reasons, mean fluxes and tendencies calculated over the entire model domain should be viewed with caution and not interpreted quantitatively as source terms in a rigorous large-scale momentum budget. The most apt interpretation of the ARPS momentum transports is that they imply a feedback from the mesoscale to the large scale. Qualitatively the behaviour of the mean transports should be reasonable, since the MCS transports in ARPS are generally greater than the momentum source terms imposed over the domain boundary zones. Furthermore, some of the drawbacks of the one-way boundary condition are reduced by considering relatively short $(6 \mathrm{~h})$ integrations which tend to minimize the interaction between MCSs and the boundary zones, and by focusing analysis on specific momentum transport structures (on the phenomenology rather than solely areal averages) over small sub-domains of the ARPS simulations. Generally these transport structures are robust enough to be apparent even near strong regions of boundary-condition forcing. Overall, our approach of focusing on the phenomenology is consistent with Houze et al. (2000).

\section{GENERAL CHARACTERISTICS OF WESTERLY ONSET AND STRONG WESTERLY REGIMES}

\section{(a) Overall context}

The warm-pool region underwent two cycles of the MJO during the TOGA COARE field project. This study focuses on the convectively active phase of the first cycle, which occurred in December 1992. The westerly onset occurred in mid December. Figure 1 shows that during 12-16 December low-level westerlies and a strong mid-level easterly jet were present over the region (Chen et al. 1996; Houze et al. 2000). MCSs began to develop during this period, though the largest MCSs in spatial and temporal dimensions occurred in the strong westerly regime characterizing the last 10 days of the month. The strong westerly regime had a strong low-level westerly jet underlying a deep layer of easterly shear (Fig. 1). Numerous MCSs categorized as 'superclusters' or 
'super convective systems' (Nakazawa 1988; Mapes and Houze 1993; Chen et al. 1996) occurred in this regime. These giant systems had large, long-lasting regions of stratiform precipitation. The hypothesis tested in this paper is that the mesoscale circulations of the stratiform regions of the superclusters affected the momentum structure of the largescale flow over a significant area (as suggested by the studies of Moncrieff and Klinker (1997) and Houze et al. (2000)).

The large-scale momentum field in turn has a significant effect on the degree of mesoscale organization that the convection attains. Wind shear at low levels interacts with the horizontal vorticity arising from convectively generated pools of cold air in the boundary layer (Rotunno et al. 1988) and can be an important factor in explaining the long duration of MCSs. Both large-scale and mesoscale-induced low-level convergence may influence the location and motion of MCSs. Upper-level shear is important for its ability to advect ice particles far from the deep convective region, enabling the creation and maintenance of broad regions of stratiform precipitation (Houze 1993). The degree of mesoscale organization may be influenced by other aspects such as SST, since the most extensive MCSs tend to be observed over the western Pacific and Indian Ocean warm pools (Chen and Houze 1997b).

The model simulations discussed in this paper focus on three MCSs: one occurred in the westerly onset regime and the other two in the strong westerly regime. The westerly onset MCS occurred on 14 December 1992 in the region outlined by the box in Fig. 2(a). This MCS was observed in detail by airborne Doppler radar (Kingsmill and Houze 1999). Because of the spatial and temporal intermittency of the tropical oceanic convection and the scarcity of observed initial conditions for the mesoscale model, the model does not produce an exact replica of the observed MCS; however, a system arises in the simulation with structural and behavioural characteristics reasonably similar to the MCS observed by aircraft (Mechem et al. 2002). The strong westerly MCS simulation was carried out for the conditions on 23-24 December 1992, during a period when large MCSs were observed by shipborne radar (Houze et al. 2000). Figure 2(b) shows a region of the simulation domain dominated by mesoscale convergence and strong westerlies over the north-east portion of the MM5 domain during the strong westerly phase. A simulated MCS with properties similar to the observed MCSs occurred in this region of the domain. The north-easterly winds over the northern region of the box are part of the Rossby gyre located toward the north of the westerlies (see Fig. 8(j) in Chen et al. (1996) and Fig. 1(b) in Mechem et al. (2002)).

The ARPS domains indicated by the boxes in Figs. 2(a) and (b) are roughly scaled by the characteristic degree of mesoscale organization for each large-scale regime. The supercluster conditions of late December are associated with larger and longer-lasting regions of convection (see the size versus lifetime relationship in Fig. 9 of Chen and Houze (1997a)) in contrast to the more isolated MCSs of the mid-December westerly onset conditions. The domain in the strong westerly simulation is large enough in northsouth extent to be able to capture convection in the pure westerlies as well as that farther north, located closer to the Rossby gyre region.

MM5 output from simulations over the TOGA COARE large-scale array provided initial and boundary conditions for the ARPS cloud model. The MM5 was initialized at 0000 UTC 14 December 1992 for the westerly onset simulations and at 1200 UTC 23 December 1992 for the strong westerly simulations. Domain-mean profiles of the MM5 wind fields in Fig. 3 agree reasonably well with the observed wind field in Fig. 1 for the two regimes. Although the spatial patterns in Figs. 2(a) and (b) show that the $850 \mathrm{hPa}$ level westerly wind components are generally stronger in late December, the mean zonal velocity at the surface is strongly modulated by the MM5-generated convective cold 
(a)
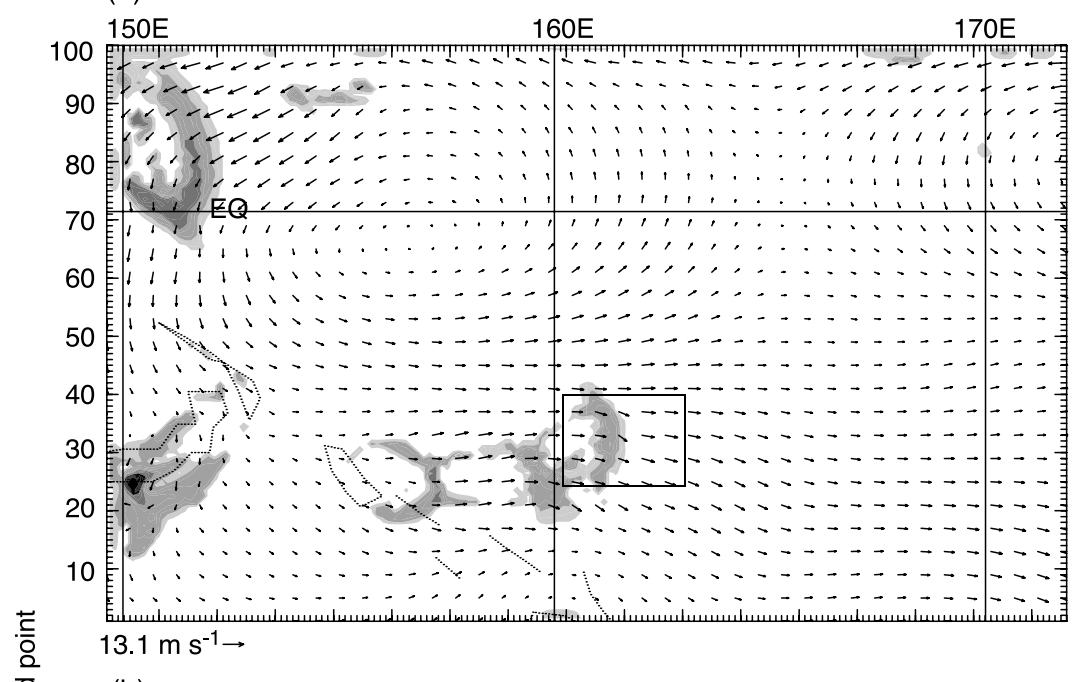

(b)

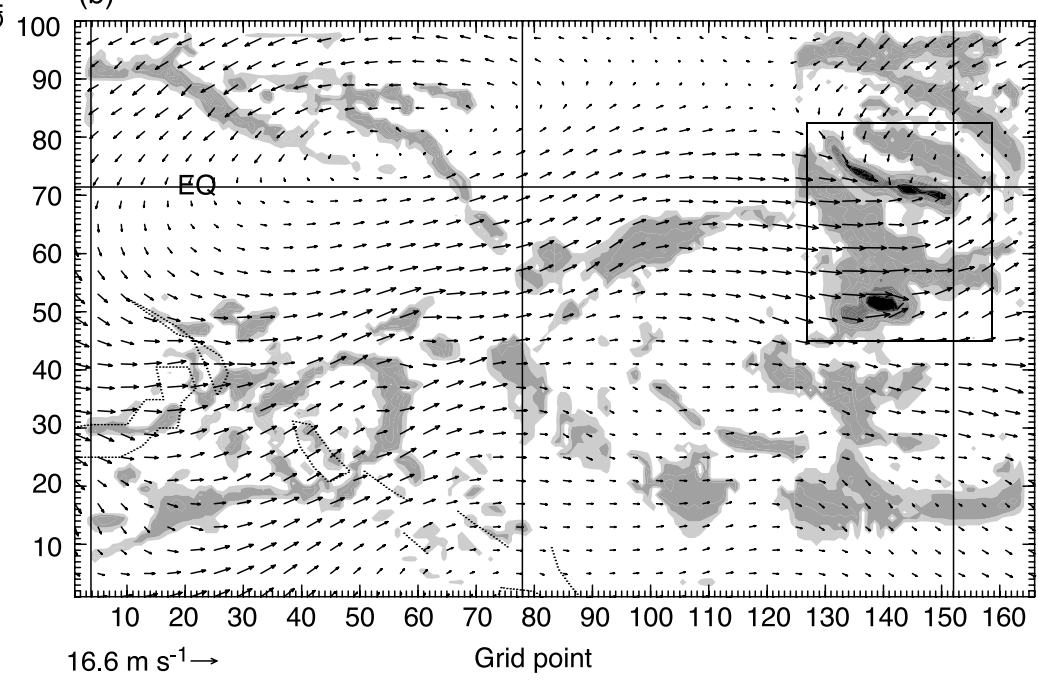

$16.6 \mathrm{~m} \mathrm{~s}^{-1} \rightarrow \quad$ Grid point

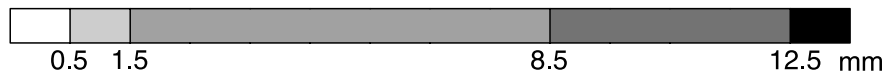

Figure 2. Horizontal cross-sections of $850 \mathrm{hPa}$ wind (vector arrows) and hourly accumulated surface rainfall (shading) from the $15 \mathrm{~km}$ grid of the fifth generation Penn State University/National Center for Atmospheric Research non-hydrostatic mesoscale model (MM5) simulations: (a) 0800 UTC 14 December 1992. (b) 2000 UTC 23 December 1992. Boxes indicate location of the Advanced Regional Prediction System (ARPS) cloud model domains. Velocity scales are at the lower left of each panel. See Mechem et al. (2002) for more details.

pools in both the westerly onset and strong westerly regimes. The mid-level easterly jet in the onset phase of the KR wave (Fig. $3, \sim 5.5 \mathrm{~km}$ level) is deficient in strength compared to the observations. In order to examine the momentum transport by MCSs within the large-scale environment that is representative of realistic conditions observed in COARE, we enhanced the mid-level easterly momentum in the MM5 wind fields using a Gaussian profile, centred at $5.5 \mathrm{~km}$ with a standard deviation of $750 \mathrm{~m}$. The resulting mid-level wind changed from the original $5-6 \mathrm{~m} \mathrm{~s}^{-1}$ easterly to $12 \mathrm{~m} \mathrm{~s}^{-1}$ easterly, which is in good agreement with the observed 5-day running-mean value of 


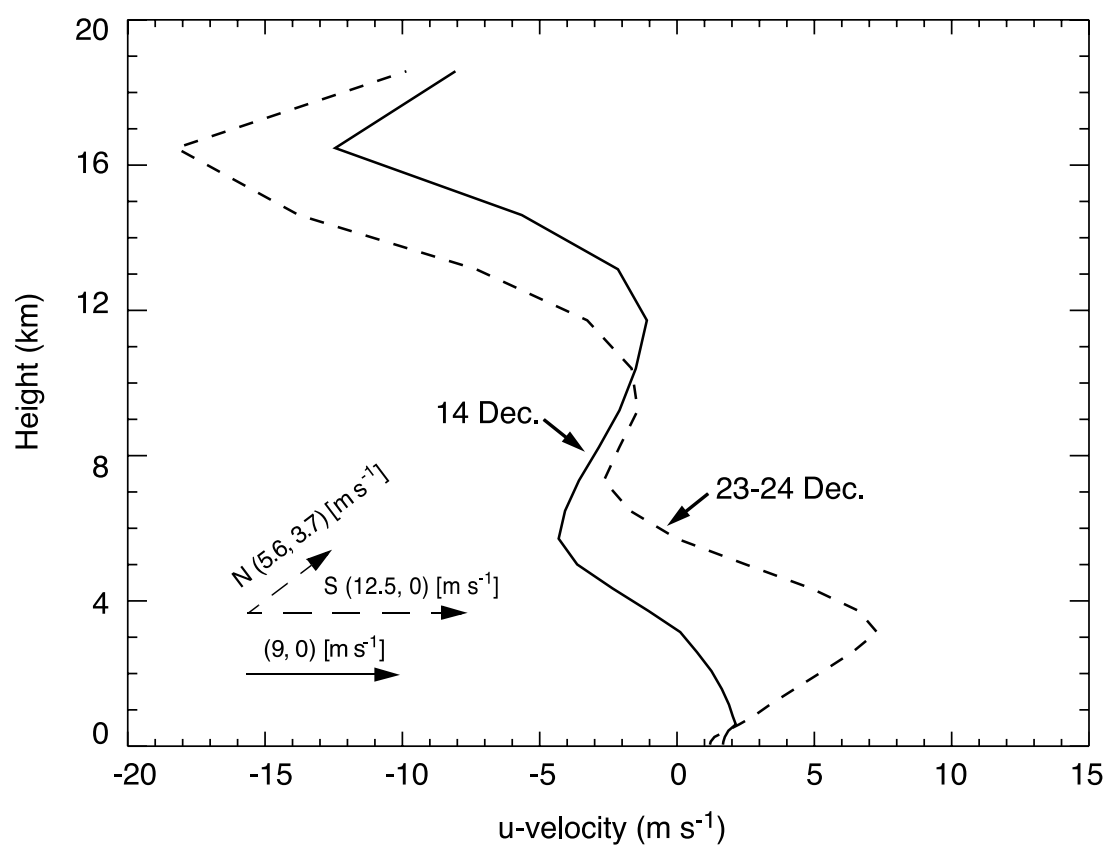

Figure 3. Vertical profiles of mean zonal velocity over the fifth generation Penn State University/National Center for Atmospheric Research non-hydrostatic mesoscale model (MM5) domain for the 14 December and 23-24 December 1992 cases at the initial time. Vectors indicate estimated mean motions for the 14 December mesoscale convective systems (MCSs) and the northern (N) and southern (S) MCSs on 23-24 December.

$\sim 10 \mathrm{~m} \mathrm{~s}^{-1}$ averaged over the IFA (Fig. 3 of Lin and Johnson (1996)). The Gaussian profile was added to all of the MM5 wind fields prior to pre-processing by ARPS, so that the modified wind field would be used consistently for both initial and boundary condition data.

\section{(b) Synopsis of simulations}

Mechem et al. (2002) discuss in detail the simulations of both westerly onset and strong westerly MCSs, and compare the simulations with observational data collected during TOGA COARE. In the westerly onset case (14 December), the forcing associated with the mesoscale convergence (Fig. 4(a)) is strong and deep, extending from just above the surface to $12.6 \mathrm{~km}$, and is accompanied by a significant cold pool (Fig. 4(b)). Data over $10 \mathrm{~km}$-wide zones that correspond to regions of boundary condition forcing have been omitted in all relevant figures. Despite this, some artifacts of the imposed boundary condition forcing are still visible, for example the $300 \mathrm{~K}$ contour near the northern boundary of Fig. 4(d). Larger simulation domains would help alleviate these artifacts though they are at present computationally prohibitive.

The mesoscale forcing ultimately leads to a broad band of convection a few hours later (Fig. 4(c)). New cells are triggered periodically, and the system strengthens and becomes more organized. After about $3 \mathrm{~h}$, the convective region begins to weaken as the cold pool propagates to the east faster than the convective precipitation, effectively outrunning the convective line (Figs. 4(d), (f) and (h)). Lacking new convective cells triggered by a cold pool, significant stratiform precipitation of variable intensity remains during this period (Figs. 4(e) and (g)). The later stages of the MCS do not display a linear pattern of convective elements; however, such a signal is not a necessary condition 
(a) $\mathrm{t}=\mathrm{Oh}$

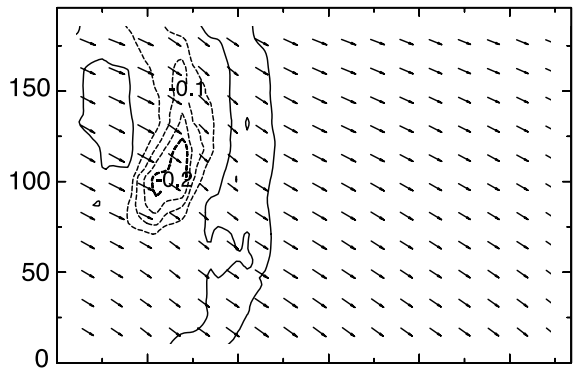

(c) $\mathrm{t}=3 \mathrm{~h}$
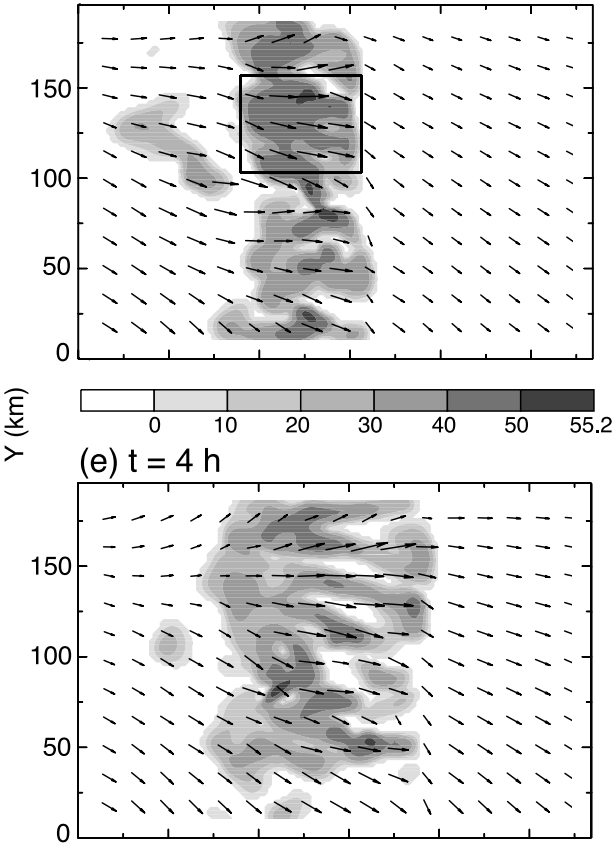

(g) $\mathrm{t}=5 \mathrm{~h}$

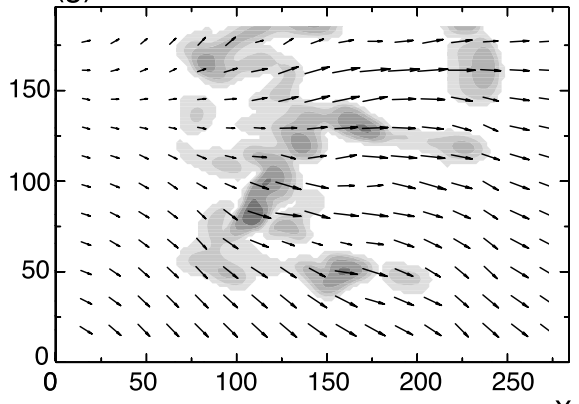

(b)

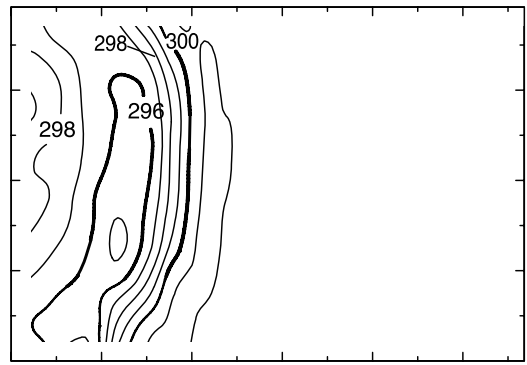

(d)

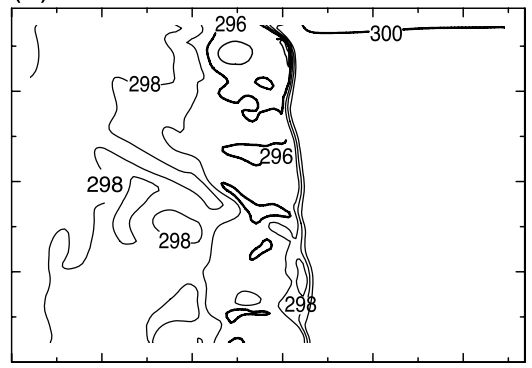

(f)

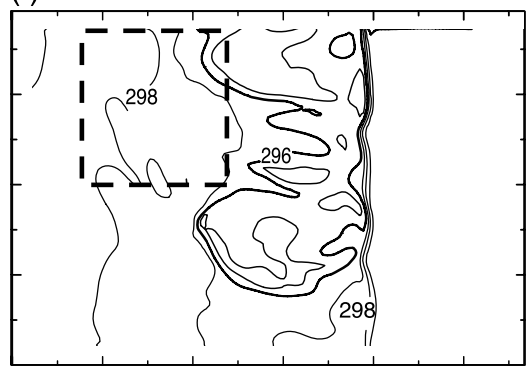

(h)

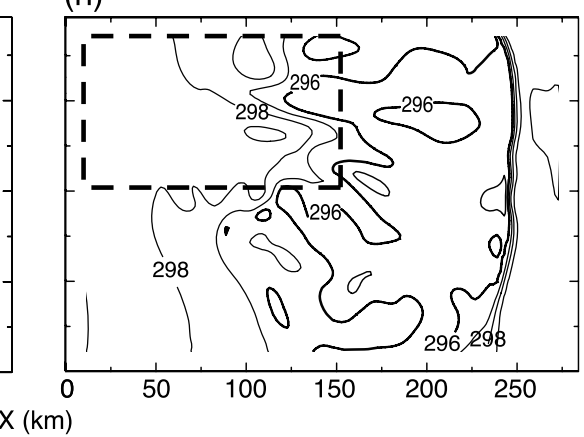

Figure 4. For the 14 December 1992 model simulation: (a) model-derived radar reflectivity (grey scale in dBZ) and wind vectors at $1 \mathrm{~km}$ altitude at the start of the simulation at time $t=0 \mathrm{~h}$; (b) surface potential temperature (contour intervals of $1 \mathrm{~K}$ ) at $t=0 \mathrm{~h}$; (c) and (d) are as (a) and (b) but at $t=3 \mathrm{~h}$; (e) and (f) are similar but at $t=4 \mathrm{~h}$; and (g) and (h) are similar but at $t=5 \mathrm{~h}$. Divergence $\left(10^{-3} \mathrm{~s}^{-1}\right)$ at $1 \mathrm{~km}$ is overlaid in (a). The solid rectangle in (c) identifies enhanced westerlies in the convective region, whilst dashed boxes in (f) and (h) roughly denote the stratiform region where descending mid-level inflow develops and where the mean profiles in Fig. 6 
for a significant area of stratiform precipitation to form and exhibit a strong mesoscale circulation (Houze 1997; Kingsmill and Houze 1999; Houze et al. 2000). It will be shown that an organized mesoscale flow underlies the complex pattern of stratiform precipitation in Fig. 4(e).

Patterns of the low-level $(1 \mathrm{~km})$ convergence (Fig. 5(a)) indicate the initial forcing of the 23-24 December strong westerly simulation. Convection over the southern subdomain ( $\mathrm{S}$ in Fig. 5) acquires a squall-line type of reflectivity pattern and rapidly moves toward the east-north-east. After $3 \mathrm{~h}$, two extensive regions of precipitation are oriented from north-west to south-east in the northern subdomain ( $\mathrm{N}$ in Fig. 5(c)). These bands move toward the north-east, with the mean flow, while new convection is triggered in a nearly continuous manner on the leading (north-eastern) edge of the cold pool. Figure 5(e) shows that the northern system remains highly organized, even after $5 \mathrm{~h}$. The cold pool is weak $(\sim-2 \mathrm{~K})$ and propagates slowly toward the north-east (Figs. 5(b), (d) and (f)) over the subdomain $\mathrm{N}$, triggering new convective elements that coexist with the decaying stratiform region. The initial and boundary conditions from the MM5 fields appear to impose an organized mesoscale circulation on the simulation in the strong westerly case.

\section{(c) Mean flow evolution in the westerly onset and strong westerly regimes}

Figure 4 shows the development of the radar reflectivity and winds at the $1 \mathrm{~km}$ level, along with the potential-temperature field, for the westerly onset simulation. The boxed region in Fig. 4(c) shows an example section of the strong convective region, characterized by large values of reflectivity and enhanced westerlies. In contrast, the stratiform regions behind (to the west of) the convective zone in the westerly onset period are accompanied by a region of decreased westerlies, evident in Figs. 4(e) and (g) in the regions corresponding to the dashed boxes in Figs. 4(f) and (h).

Figure 5 shows the evolution of the low-level wind, reflectivity, and potentialtemperature field within the MCS in the strong westerly regime. In contrast to the westerly onset MCS of Fig. 4, this MCS appears to increase the low-level westerly wind component throughout the whole MCS, in both convective and stratiform regions.

Momentum transport by convection has often been investigated by assuming that the convection has a quasi-linear shape and then analysing the transport components in the line-normal and line-parallel directions. In this study only the zonal component is addressed, because the MCS geometry is not always easy to define and the largest variability is normally in the zonal direction. Additionally, upscale feedback processes over the TOGA COARE region are most useful when framed in terms of the zonal component since it largely defines the structure of the KR wave pattern.

We examine the tendency of the flow to become more westerly or easterly with time in terms of either the total zonal wind field $u(x, y, z, t)$, where $x, y$ and $z$ are conventional orthogonal coordinates and $t$ is time, or the perturbation of this wind from its initial state value. Since the initial wind field is spatially inhomogeneous in our calculations with the ARPS model, we define perturbation zonal wind velocity as:

$$
u^{\prime}(x, y, z, t)=u(x, y, z, t)-u_{0},
$$

where $u_{0}=u(x, y, z, t=0)$ is a fully $3 \mathrm{D}$ base state. The more traditional choice for the base state, where it is defined as a horizontal average of the initial field, would introduce perturbations (spatial fluctuations) into the initial $u^{\prime}$ field and thus make the interpretation of evolution difficult.

We let the operator \langle\rangle indicate an average at a given time over one of the boxes shown in Figs. 4(f) and (h), and Figs. 5(d) and (f). The boxes roughly represent 
(a) $\mathrm{t}=0 \mathrm{~h}$

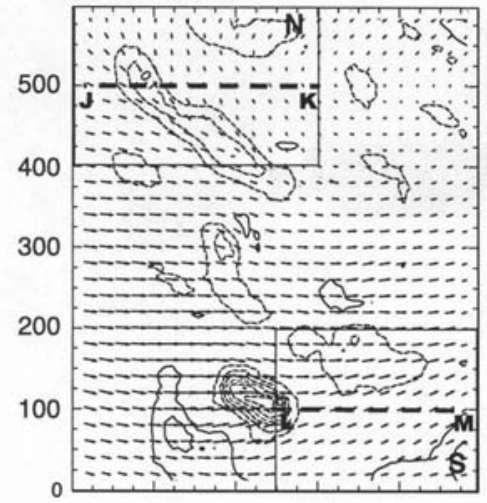

(c) $\mathrm{t}=3 \mathrm{~h}$

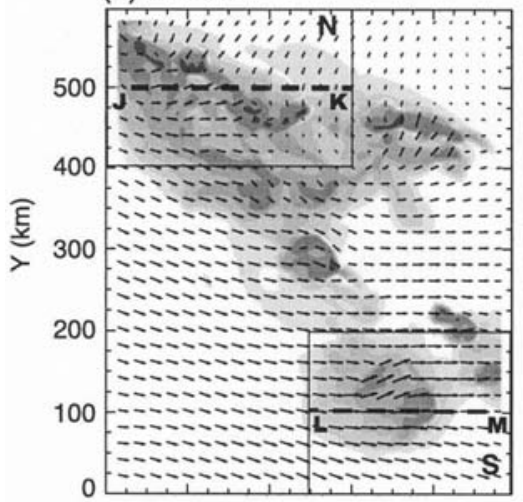

(e) $\mathrm{t}=5 \mathrm{~h}$

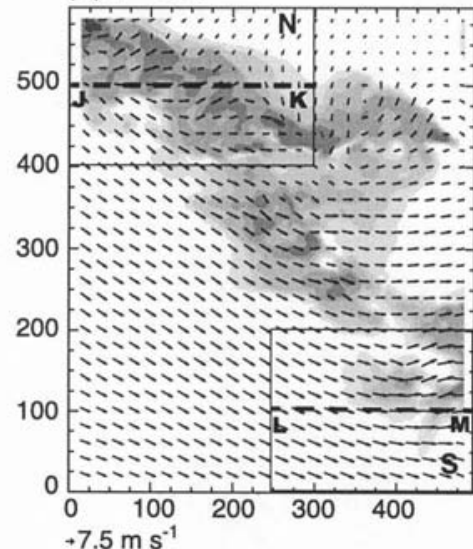

(b)

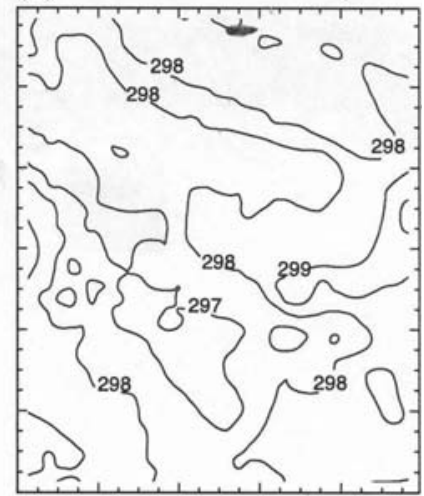

(d)

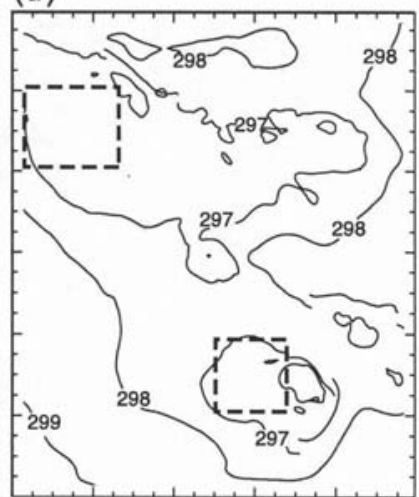

(f)

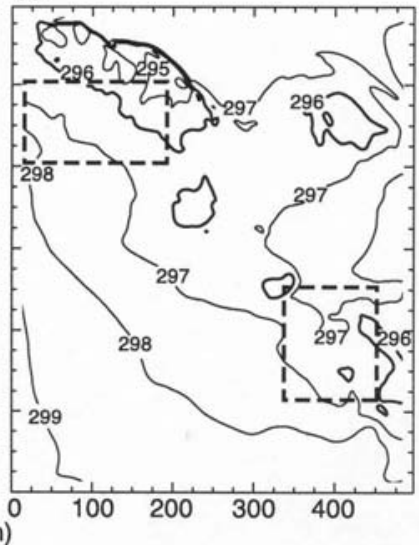

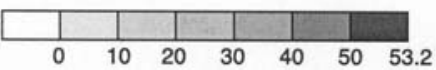

Figure 5. Same as in Fig. 4 but for 23-24 December 1992 simulation and not including $t=4 \mathrm{~h}$ frames. Northern and southern subdomains are indicated by $\mathrm{N}$ and S. Dashed lines JK and LM indicate the locations of cross-sections shown in Fig. 7. Divergence $\left(10^{-3} \mathrm{~s}^{-1}\right)$ at $1 \mathrm{~km}$ is again overlaid in (a), whilst dashed boxes in (d) and (f) roughly denote the stratiform regions over northern and southern subdomains where descending mid-level inflow develops and where the mean profiles in Fig. 6 are calculated. 
(a) 14 Dec. 1992

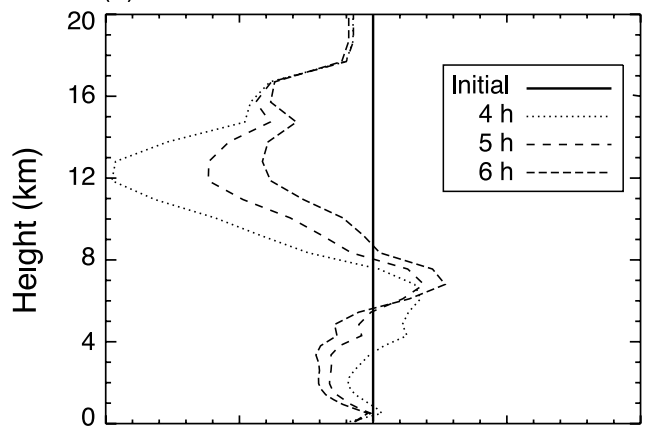

(b) 23-24 Dec. 1992 (South)

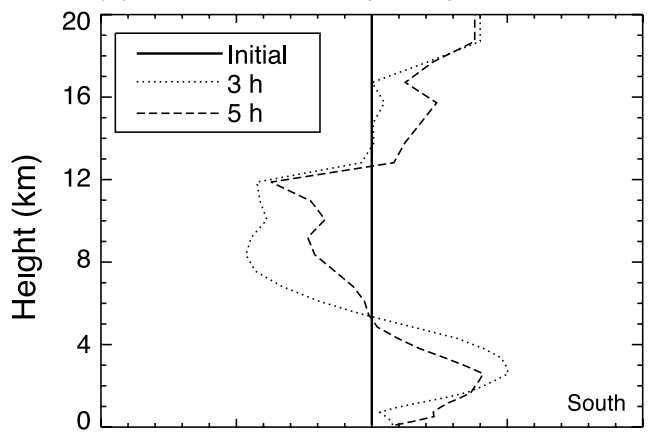

(c) 23-24 Dec. 1992 (North)

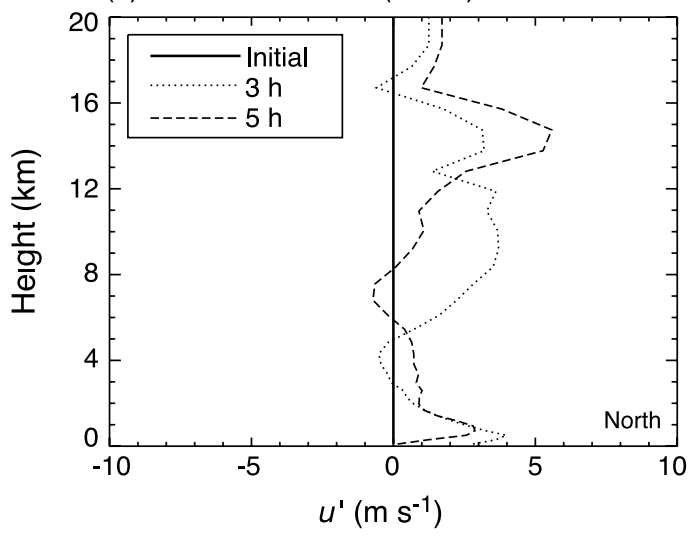

Figure 6. Evolution of mean profiles of $u^{\prime}$, as defined in the text, for: (a) the 14 December 1992 simulations; (b) the southern subdomain of the 23-24 December 1992 simulations; (c) as (b) but the northern subdomain. For each case, calculations are made over the stratiform regions denoted by the moving dashed boxes in the potentialtemperature cross-sections of Figs. 4 and 5.

stratiform regions, well separated from the 10-20 km wide convective region. Figure 6 shows the time variation of $\left\langle u^{\prime}\right\rangle$ for both the westerly onset case (Fig. 6(a)) and the strong westerly case (Figs. 6(b) and (c)). As long as the boxes are located within the stratiform area and well away from the active convective elements at the front of the line, the averages are relatively insensitive to moderate changes in box size and location. We focus on the stratiform regions of the MCSs because our primary objective is to explore the impact of the stratiform region momentum field on the larger-scale environment. Because of the way $u^{\prime}$ is defined, the initial profiles are zero. The vertical profiles of $\left\langle u^{\prime}\right\rangle$ in Fig. 6(a) show that in the westerly onset MCS, the perturbation zonal momentum becomes more easterly with time in the stratiform-region layer from just above the surface to a height of $\sim 5.5 \mathrm{~km}$, approximately the level of the easterly jet maximum. In contrast, the vertical profiles in Figs. 6(b) and (c) show that in the strong westerly case the zonal momentum in the stratiform-region layer between the surface and $\sim 5 \mathrm{~km}$ becomes more westerly with time. These statistics confirm quantitatively the low-level stratiform features visible in the Figs. 4 and 5 wind fields that suggest the stratiformregion momentum tendencies in the two flow regimes differ in some fundamental way. This result is consistent with the suggestion of Houze et al. (2000) that the stratiformregion circulations of MCSs tend to be a negative feedback to the development of 
low-level westerlies in the westerly onset regime and a positive feedback on the lowlevel westerlies in the strong westerly regime. The next two sections investigate the mechanisms by which the large-scale zonal momentum structure is modified by MCSs in the strong westerly and westerly onset regimes of the MJO.

\section{MOMENTUM TRANSPORT IN STRATIFORM REGIONS DURING THE STRONG WESTERLY PHASE}

We now depart from the chronological order of cases and discuss the strong westerly case first and the westerly onset case second, since the MCS in the strong westerly regime has a simpler mid-level inflow structure, resembling that of the classic leading-line/trailing-stratiform squall-line paradigm (e.g. Houze et al. 1989). The more complex structure of the MCS in the westerly onset regime becomes clear when seen in light of its difference from the MCS of the strong westerly regime.

\section{(a) Evolution of the zonal wind component}

The mean zonal wind profile of the strong westerly regime is marked by a maximum of westerly winds at low levels (Fig. 1). This westerly jet lies in the lower tropospheric layer of air that enters the stratiform regions of MCSs as mid-level inflow (Kingsmill and Houze 1999). As each large MCS in this environment evolves, it transports the momentum of the low-level westerly jet into the stratiform region and then downward in the mesoscale downdraught of the MCS. This behaviour is seen particularly well in the full momentum field $(u)$ in zonal cross-sections through the simulated MCSs in both the southern and northern subdomains. In Fig. 7, arrows highlight regions of downward transport of westerly momentum. Houze et al. (2000) documented a similar structure in Doppler radar observations of MCSs in the strong westerly period of TOGA COARE, and suggested that the observed flow features likely resulted from simple downward transport of momentum, possibly combined with the MCS-generated perturbation pressure field accelerating the inflow downward (similar to the mechanism suggested by Smull and Houze (1987)).

West-east cross-sections in Fig. 8 showing the perturbation momentum $u^{\prime}$ and related fields provide insight into the dynamics of the downward-sloping mid-level inflow structure in the MCSs. Figure 8 shows the evolution of $u^{\prime}$ in the southern MCS at 3 and $4 \mathrm{~h}$. The cross-sections taken through the MCS show a widespread contiguous hydrometeor pattern (shaded fields in Figs. 8(e) and (f)) strongly reminiscent of the prototypical 2D squall-line circulation (Houze et al. 1989). This simulated MCS in Fig. 8 closely resembles squall-line-like systems observed during the strong westerly phase of TOGA COARE by shipborne radar on the NOAA ship Vickers (see Fig. 21 of Houze et al. (2000)). By definition, the initial field is zero; therefore, structures are the result only of convection and/or boundary forcing. The dashed box in the vertical crosssections of $u^{\prime}$ at $3 \mathrm{~h}$ (Fig. 8(c)) outlines a zone of upward transport of momentum near the active convection. This region contains a significant, elevated pocket of westerly velocity perturbation. This pocket of enhanced positive $u^{\prime}$ is produced at early times in the vicinity of a strong convective updraught and results from upward vertical transport of westerly momentum associated with the low-level jet structure. The situation in the northern subdomain (not shown) is more complex, but also exhibits upward transport of westerly momentum by the stronger updraughts. The perturbation pressure field for both systems is consistent with a hydrostatic response to a convective heating maximum overlying a near-surface cold pool. For example, the perturbation pressure minimum at $3 \mathrm{~km}$ over the southern subdomain at $3 \mathrm{~h}$ (Fig. 8(e)) accelerates the front-to-rear and 

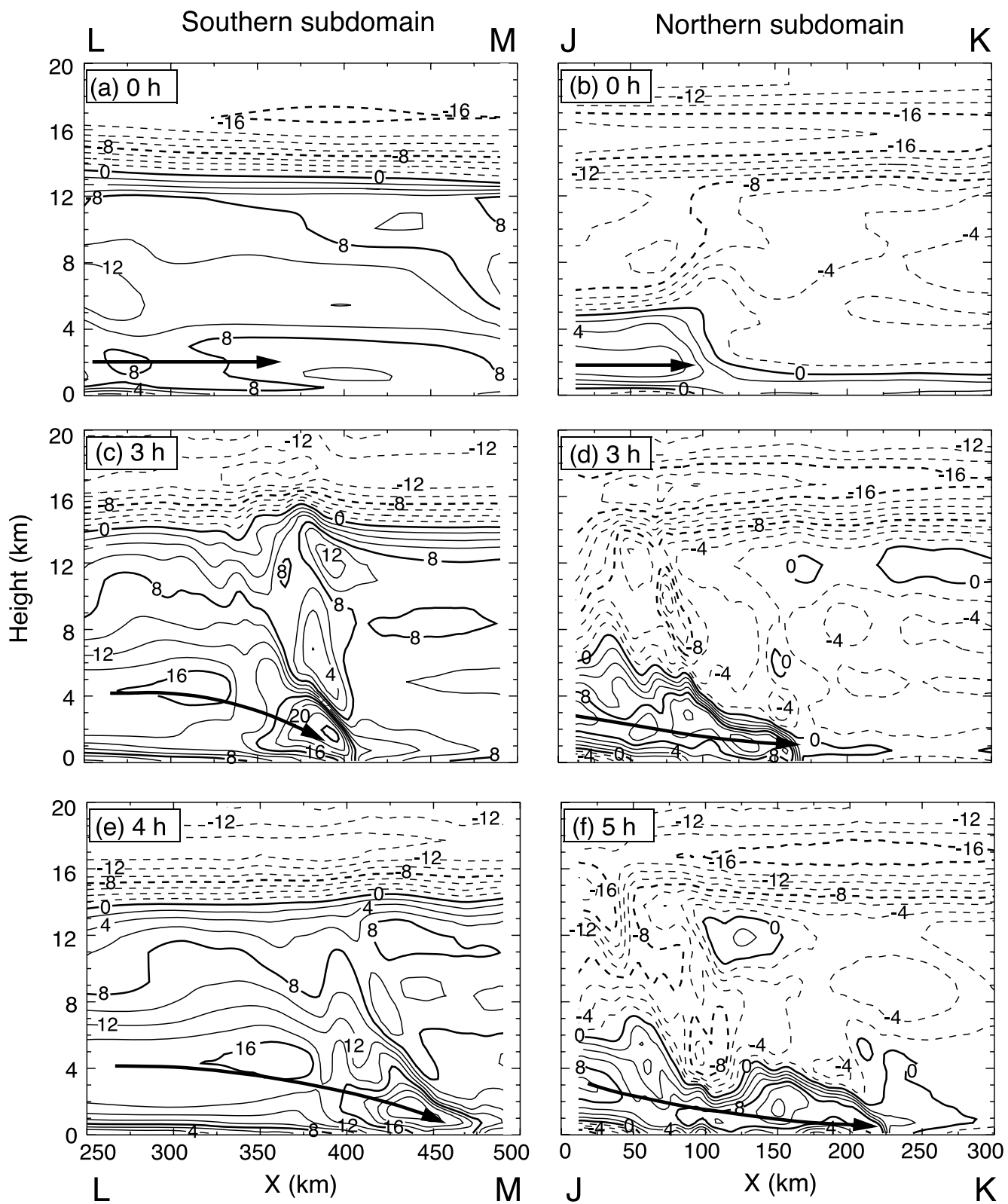

Figure 7. Cross-sections of zonal velocity, $u\left(\mathrm{~m} \mathrm{~s}^{-1}\right)$ for the 23-24 December 1992 simulation: (a) along line LM in the southern subdomain of Fig. 5 at initialization time $t=0$; (b) along line JK in the northern subdomain of Fig. 5 at $t=0$; (c) and (d) as (a) and (b), respectively, but at $t=3 \mathrm{~h}$; (e) and (f) as (a) and (b) but at $t=4$ and $5 \mathrm{~h}$. Dashed contours are negative (easterly). Arrows emphasize descending mid-level inflow layer. 

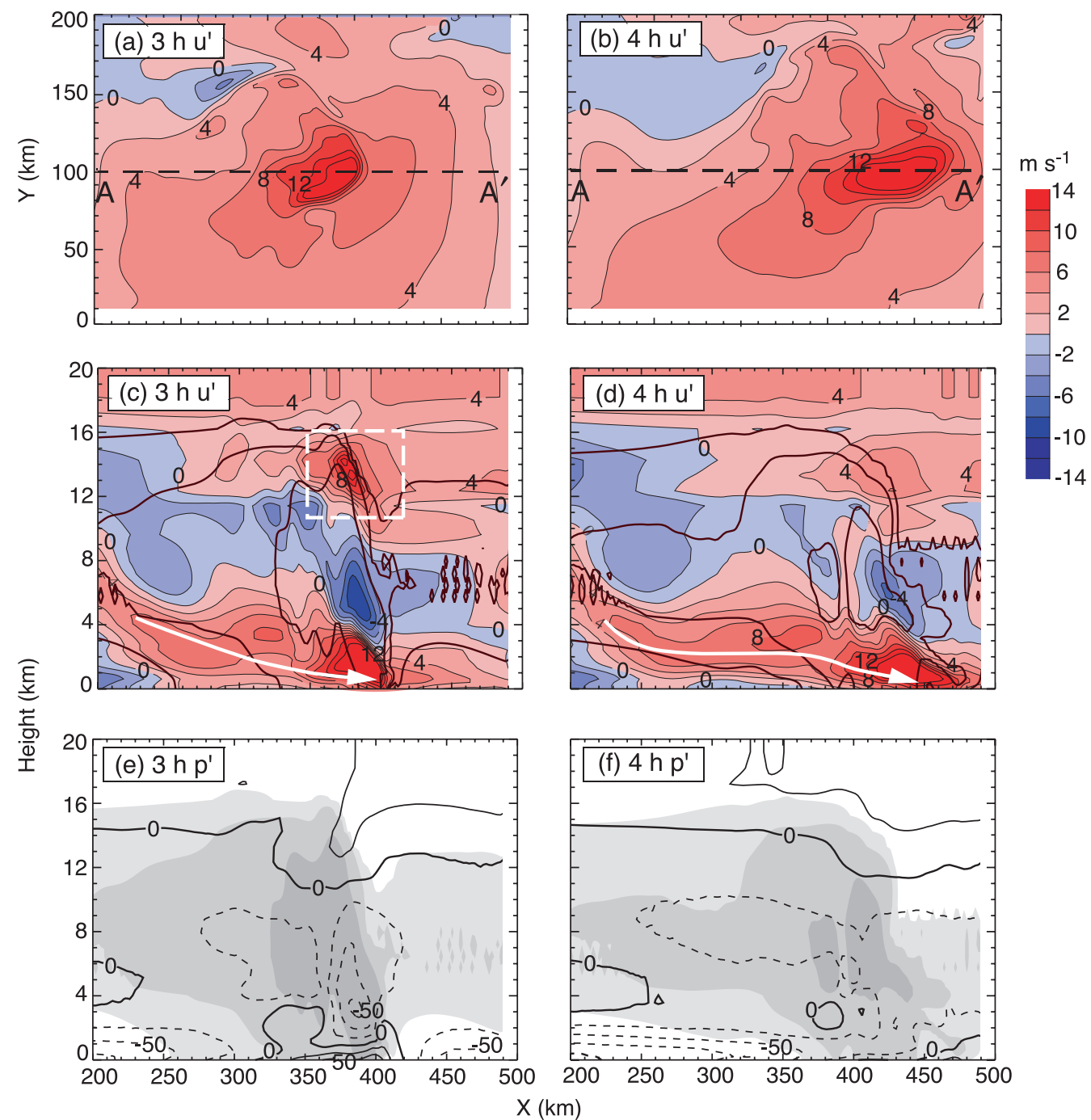

Figure 8. Cross-sections of model-simulated fields at 3 and $4 \mathrm{~h}$ over the southern subdomain S (shown on Fig. 5) for the 23-24 December 1992 simulation: (a) filled contours of perturbation zonal velocity $u^{\prime}$, as defined in the text, at height $z=1 \mathrm{~km}$ at $3 \mathrm{~h}$; (b) as (a) but at $4 \mathrm{~h}$; (c) vertical cross-section of $u^{\prime}$, taken through the dashed line $\mathrm{AA}^{\prime}$ in (a) at $y=100 \mathrm{~km}$, at $3 \mathrm{~h}$; (d) as (c) but at $4 \mathrm{~h}$. The contour interval for $u^{\prime}$ is $2 \mathrm{~m} \mathrm{~s}^{-1}$, with shades of red indicating positive (westerly) perturbations and shades of blue negative (easterly) perturbations. (e) Contours of perturbation pressure along $\mathrm{AA}^{\prime}$, overlaid on shaded total hydrometeor content, at $3 \mathrm{~h}$ (the contour interval is $2.5 \mathrm{hPa}$ ); (f) as (e) but at $4 \mathrm{~h}$. Contours of the total hydrometeor content (levels of $10^{-5}, 10^{-4}, 10^{-3} \mathrm{~kg} \mathrm{~kg}^{-1}$ ) are overlaid on (c), (d), (e) and (f) to indicate the general location of the convection. The dashed box is described in the text. Arrows emphasize perturbation flow.

rear-to-front inflows in the manner described by LeMone (1983). The negative region of $u^{\prime}$ at $3 \mathrm{~h}(x=380, z=5 \mathrm{~km})$ in Fig. 8 is clearly a pressure-driven flow arising from the hydrostatic perturbation low pressure. Arrows in the vertical cross-sections in Fig. 8 indicate the enhancement of $u^{\prime}$ at low levels. Despite having a more complex 3D structure, the simulated MCS in the northern subdomain (not shown) exhibits a similar pattern of upward westerly momentum transport by updraughts, as well as similar perturbation pressure effects. 


\section{(b) Momentum budget of MCSs in the strong westerly regime}

To investigate the effect of the MCS circulations on the momentum field, we write the zonal momentum equation in the form:

$$
\begin{aligned}
& \overline{\frac{\partial u}{\partial t}}=\overline{-\frac{1}{\rho} \frac{\partial p}{\partial x}}-\overline{u \frac{\partial u}{\partial x}}-\overline{v \frac{\partial u}{\partial y}}-\overline{w \frac{\partial u}{\partial z}}-\overline{D_{u}}, \\
& \text { TEN } \text { PGA }
\end{aligned}
$$

where $p$ is pressure, $\rho$ is air density, $w$ is vertical velocity, and $D_{u}$ is subgrid-scale mixing. From left to right, the terms (as indicated below (2)) are: the momentum tendency (TEN), pressure gradient acceleration (PGA), horizontal advection (HA), vertical advection (VA), and subgrid-scale effects (SGS). The terms on the right-hand side are calculated from 2-minute model output. A time average is defined as:

$$
\overline{(~)}=\int_{T_{1}}^{T_{2}}(\mathrm{)} t,
$$

with $T_{2}-T_{1}=30$ minutes.

VA over the southern and northern subdomains, averaged over the 30 minute interval from 4.5-5 $\mathrm{h}$ and plotted in Fig. 9, includes widespread regions of positive forcing at an altitude of $1 \mathrm{~km}$ within the dashed boxes. The momentum budgets in the regions enclosed by boxes are largely determined by the mesoscale vertical velocity pattern within the stratiform region. The height of maximum environmental westerlies is lower than the vertical velocity maximum (peak just below the melting level) but enough overlap is present to produce downward transport of westerly momentum in both regions. The late stage of the system is characterized by a broad region of mesoscale descent, a significant area of which is covered by downward vertical velocity with magnitudes $>0.25 \mathrm{~m} \mathrm{~s}^{-1}$. The systems observed during the strong westerly phase of TOGA COARE tended to be larger and more organized in comparison to those observed during the westerly onset phase (Chen et al. 1996; Houze et al. 2000) so it is plausible that the regions of mesoscale vertical motion are also larger. In the model, the mesoscale descent arises from the melting, sublimation, and evaporation within the broad stratiform area (consistent with Yang and Houze (1995b), Braun and Houze (1997) and others). Above the area of mesoscale descent are regions of significant upward air motion with magnitudes of $w \sim 2 \mathrm{~m} \mathrm{~s}^{-1}$. This zone of elevated mesoscale ascent slopes upward toward the rear of the MCS in the same fashion as midlatitude squall lines (Houze et al. 1989; Moncrieff 1992; Houze 1993, 2004). Both northern and southern systems contain ascending and descending branches of the MCS circulation, and are generally consistent with the structure of a classic leadingline/trailing-stratiform squall-line MCS.

Trier et al. (1998) found that the magnitude of the net forcing (TEN) was generally much smaller than that of individual terms on the right-hand side of (2). To illustrate the interplay of the different terms, Fig. 10 shows the fields of VA, HA, PGA, and TEN, taken at a late stage of the southern MCS and averaged over a $50 \mathrm{~km}$ strip. The arrow in Fig. 10(a) indicates the perturbation flow shown in Fig. 8(d). The subgrid-scale term SGS is omitted, as in Yang and Houze (1996), since the turbulence term is only appreciable near strong convective updraughts and regions of detrainment in the upper troposphere.

The VA term in Fig. 10(a) has a $+/-/+$ structure. The low-level negative and positive layers are the result of a stratiform-region downdraught superimposed on the 
(a)

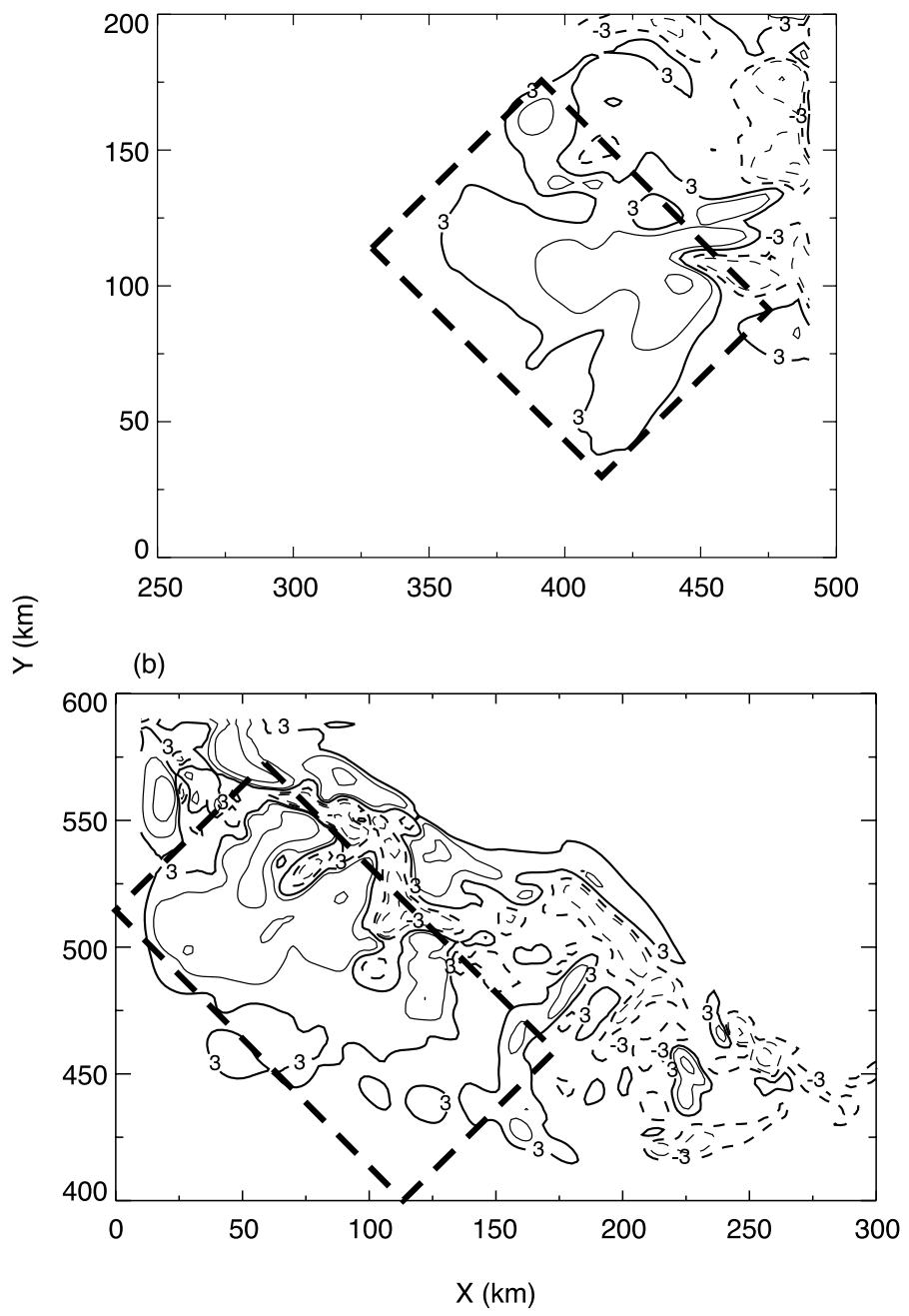

Figure 9. Horizontal cross-sections of the 30-minute time-mean $(4.5-5 \mathrm{~h})$ VA momentum acceleration term (see text) at an altitude of $1 \mathrm{~km}$ for the 23-24 December 1992 simulation: (a) southern subdomain, (b) northern subdomain. Contour values are $-17,-7,-3,3,7,17 \mathrm{~m} \mathrm{~s}^{-1} \mathrm{~h}^{-1}$; negative values are indicated by dashed contours. The boxed regions emphasize zones of organized downward transport of westerly momentum.

prevailing environmental low-level westerly jet structure. HA is out of phase with VA, with positive values at $3-6 \mathrm{~km}$. The latter are decisive in establishing a positive zone of TEN (increasing westerlies) in the 1-6 km layer (Fig. 6(b)). The quadrature relationship of VA and HA responsible for the increasing westerlies in the 1-6 km layer is consistent with the sloping nature of the descending inflow layers that is brought about by pressure accelerations during the vigorous convective stage.

Figure 10(c) might appear to suggest that the PGA is a small effect in the momentum budget in comparison with VA and HA. However, the latter terms largely offset each other, and PGA affects both the magnitude and sign of TEN (Fig. 10(d)) especially the strengthening of the low-level westerlies (Fig. 6(b)). Moreover, as discussed in connection with Fig. 8, the pressure perturbation gradient accelerates the mid-level 

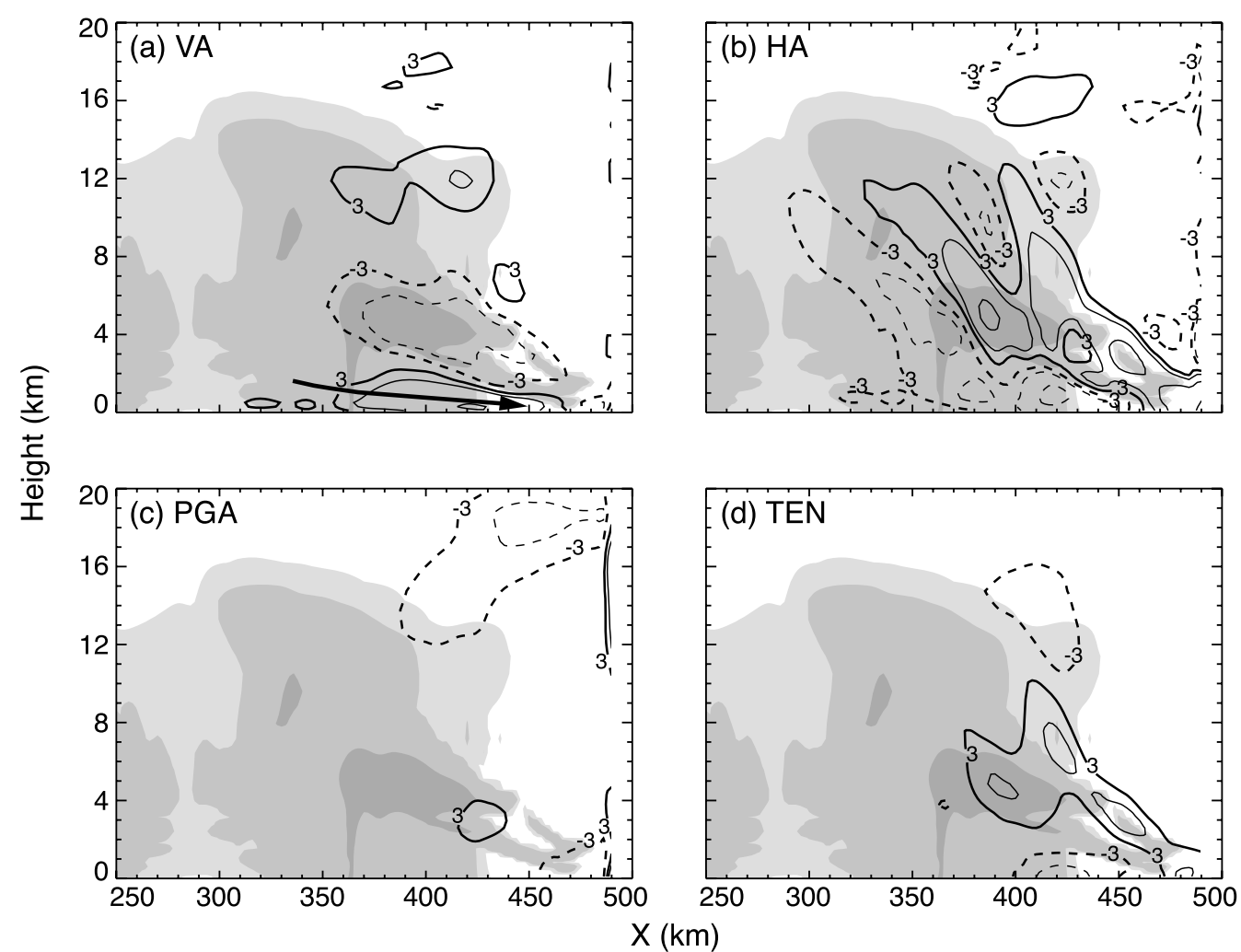

Figure 10. Vertical cross-sections of 30 minute time-mean (4-4.5 h) momentum forcing terms for the 23-24 December 1992 simulation, averaged over a $50 \mathrm{~km}$ wide strip centred at $y=100 \mathrm{~km}$ in the southern subdomain (see Figs. 8(a) and (b)) overlaid on the shaded total hydrometeor field (levels of $10^{-5}, 10^{-4}, 10^{-3} \mathrm{~kg} \mathrm{~kg}^{-1}$ ). (a) Vertical advection VA; (b) horizontal advection HA; (c) pressure gradient acceleration PGA; (d) momentum tendency TEN. Contour values are $-17,-7,-3,-1,1,3,7,17 \mathrm{~m} \mathrm{~s}^{-1} \mathrm{~h}^{-1}$, negative values are dashed. The arrow in (a) indicates perturbation flow as seen in Fig. 8(d).

inflow and thus enhances the zonal wind field that is advected by vertical and horizontal motions (VA and HA). The PGA term thus plays an indirect role in the vertical redistribution of zonal velocity that strengthens the low-level westerly flow prior to its transport. The mesoscale downdraught in the stratiform region is able to transport downward the strong pre-existing environmental westerlies and any westerlies accelerated by the MCS-generated perturbation pressure pattern.

Momentum budget terms for the northern system (not shown) exhibit similar but more complicated behaviour compared to the more $2 \mathrm{D}$ circulation in the southern system just described. In particular, the orientation of the active convective line of the southern system is normal to the mean flow and the convective momentum flux is primarily down-gradient, while the orientation of the convective line in the northern system at an angle of $\sim 45^{\circ}$ from the mean flow produces a near balance between counter-gradient and down-gradient flux.

\section{(c) MCS feedbacks in the strong westerly regime}

The above results illustrate how the MCSs occurring in the strong westerly regime act to increase the westerly zonal momentum at levels just above the surface, as a combination of VA, HA, and PGA. The increase of low-level westerlies is a positive 
momentum feedback, strengthening the already strong near-equatorial westerlies in the region between the large-scale Rossby gyres. In addition, the resulting enhanced lowlevel convergence on the eastern edge of the MCS implies a positive convective feedback to the propagating Kelvin-Rossby pattern, since the triggering of new convection would be occurring along the same direction as the propagation of the large-scale wave. Furthermore, the enhanced near-surface westerly momentum may also constitute a boundary-layer feedback by producing surface fluxes of heat and moisture favourable for convection during the strong westerly phase.

\section{MOMENTUM TRANSPORT IN STRATIFORM REGIONS DURING THE WESTERLY ONSET PHASE}

\section{(a) Evolution of the zonal wind component}

Figure 11 shows the hourly evolution of the 14 December simulation. By $3 \mathrm{~h}$, the vertical cross-section of $u^{\prime}$ shows that the flow in the upper levels of the domain associated with the convective region is strongly divergent (see box A in Fig. 11(e)) though asymmetrically so, with easterlies significantly stronger and covering more area than the westerlies. The asymmetry arises when the convective updraughts act upon the deep layer of westerly shear between 5.5 and $13 \mathrm{~km}$, biasing the momentum transport features toward easterlies. Box B outlines a small transient region of easterlies being transported upward, a feature consistent with the results of Houze et al. (2000) who found observational evidence that during the onset phase the convective updraughts consistently carried easterly momentum upward. This type of transient convective momentum transport feature is evidently responsible for the easterly bias in the divergence structure aloft.

The horizontal maps of $u^{\prime}$ in Figs. 11(a) and (b) and perturbation pressure fields in Figs. 11(i) and (j) show that from 3-4 h the cold pool propagates from $X=158 \mathrm{~km}$ to $X=200 \mathrm{~km}$ (top panels). Figure 11(e) shows that at $3 \mathrm{~h}, u^{\prime}$ at low levels just to the west of the cold-pool edge is westerly (red) and about $10 \mathrm{~m} \mathrm{~s}^{-1}$ in magnitude. The easterly perturbation flow (blue) just above the cold pool is $\sim 8 \mathrm{~m} \mathrm{~s}^{-1}$. An hour later, the lower levels behind the cold-pool edge have positive values of $u^{\prime}$ as large as $14 \mathrm{~m} \mathrm{~s}^{-1}$, while the area above these positive perturbations have negative values of $12 \mathrm{~m} \mathrm{~s}^{-1}$ (Fig. 11(f)). The perturbation pressure gradient associated with the strong convective region accelerate the mid-level inflows to the MCS. The strong cold pool produces a low-level pressure perturbation maximum, and strong latent heating dictates a hydrostatic minimum above. The result is eastward-directed pressure gradient acceleration in the cold pool and westward-directed acceleration above (between $X=$ $75 \mathrm{~m}$ and $X=160 \mathrm{~m}$ in the $3 \mathrm{~h} p^{\prime}$ field of Fig. 11(i)). The perturbation pressure pattern thus increases low-level westerlies and further strengthens the mid-level easterly jet in the vicinity of the MCS, implying a local enhancement of the environmental shear of the zonal wind with height. Because the convective region weakens significantly between 3 and $4 \mathrm{~h}$, the hydrostatic pressure minimum associated with strong latent heating (at $X=120 \mathrm{~km}$ at $3 \mathrm{~h}$ ) decreases significantly in magnitude, likely weakening the front-torear flow acceleration.

The circulation in the stratiform region of the system transports mid-level easterly momentum downward during 4-6 h of the simulation (last three columns of Fig. 11). The values of $u^{\prime}$ become negative at or just below the easterly jet maximum $(5.5 \mathrm{~km})$ and descend to the surface. The magnitude of the zonal velocity perturbation is not particularly strong $\left(4-6 \mathrm{~m} \mathrm{~s}^{-1}\right)$, but the area affected is large enough to have a large-scale impact (as shown in section 6). The transition at the surface from westerly to easterly perturbation flow (represented by the arrows in Figs. 11(g) and (h)) occurs somewhat 

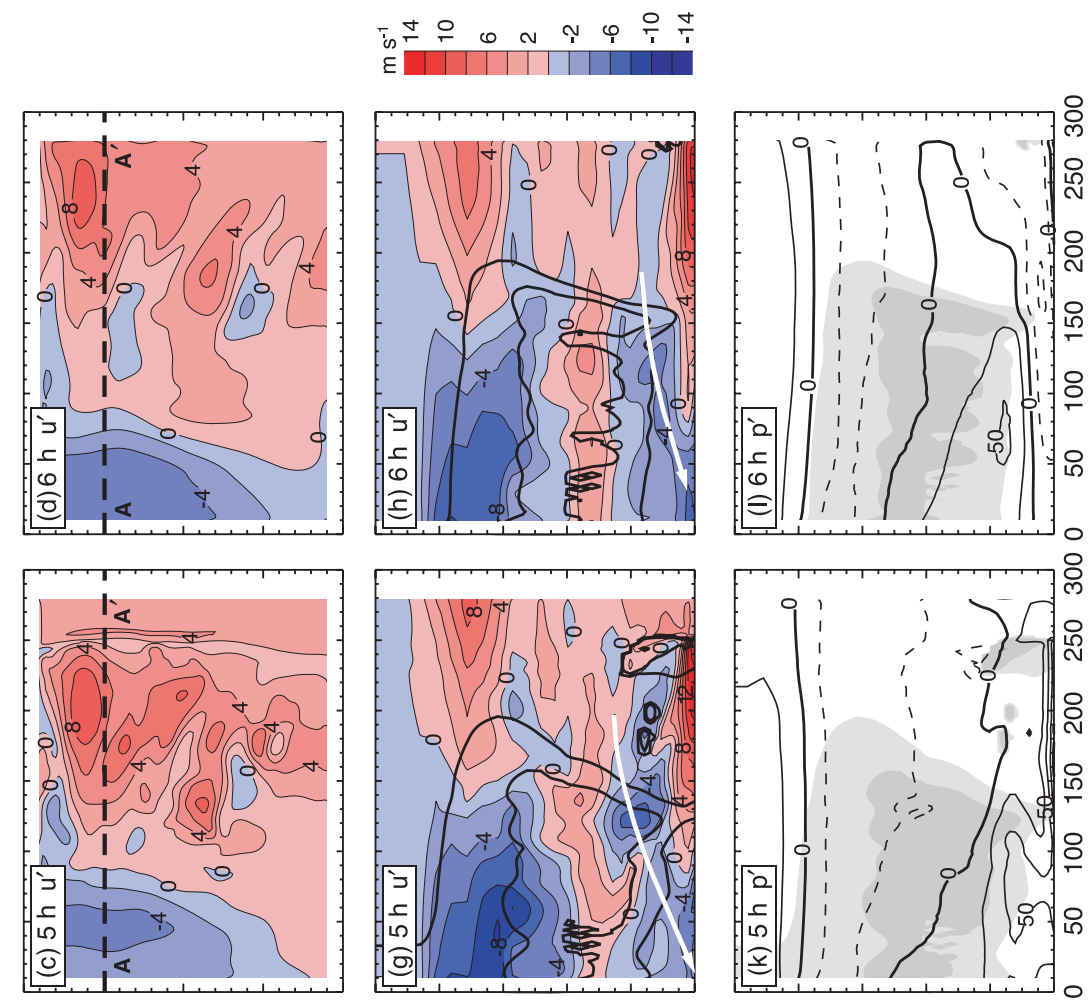

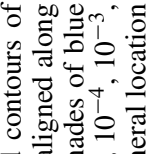

준

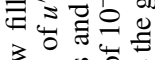

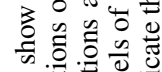

ใै

चี

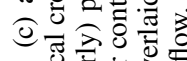

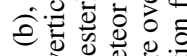

कิ

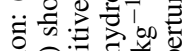

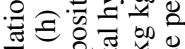

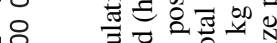

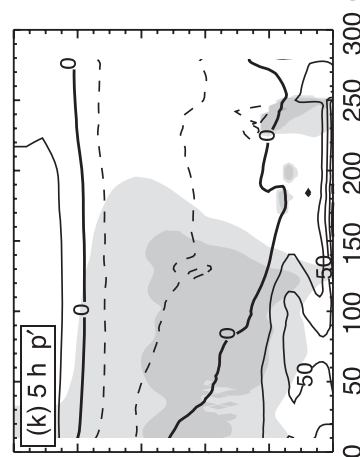

灵

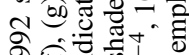

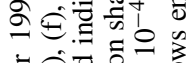

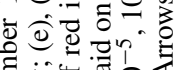

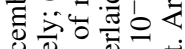

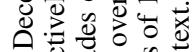

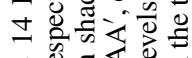

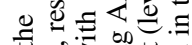

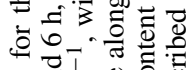

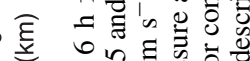
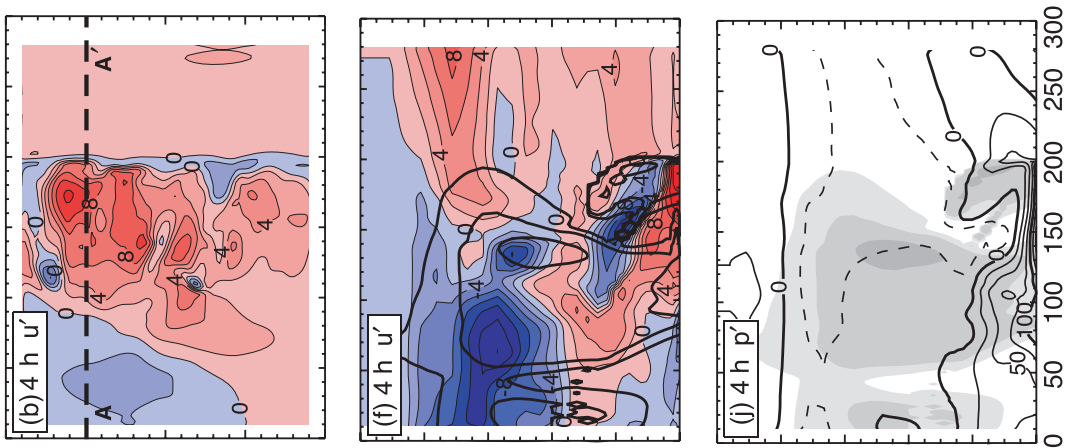

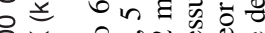

mind

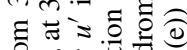

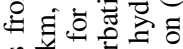

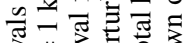

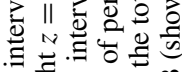

대을

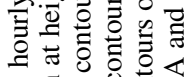

त.

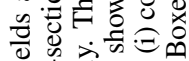

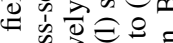
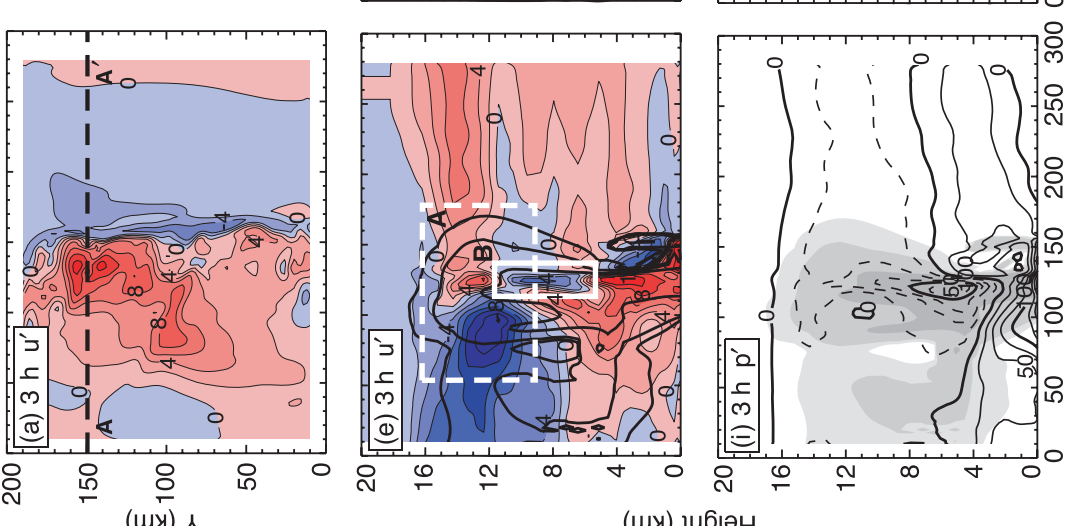

원

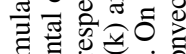

i.

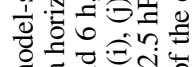

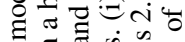

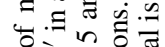

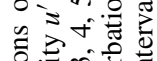

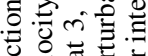

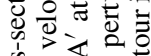

它要远

U 유.

ㄱ.월

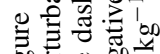

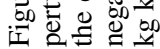




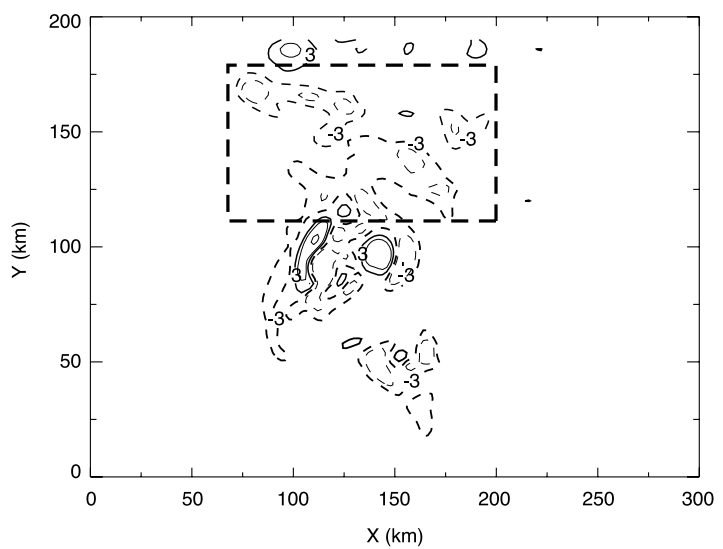

Figure 12. Horizontal cross-section of the 30-minute time-mean (5-5.5 h) vertical advection (VA) momentum acceleration term at an altitude of $2.5 \mathrm{~km}$ for the 14 December 1992 simulation. Contour values and units are as in Fig. 9. The box emphasizes a region of organized downward transport of easterly momentum.

abruptly, in a manner similar to that seen in single-Doppler radar observations (Houze et al. 2000; Houze 2004) where easterly flow periodically pulsed down into the boundary layer (see Fig. 44 of Houze (2004)).

\section{(b) Momentum budget of MCSs in the westerly onset regime}

The same procedure as described in the previous subsection is applied to the strong westerly case in subsection 4(b); we examine the spatial structure of the momentum forcing to determine the processes responsible for the zonal velocity becoming more easterly at low levels, from just above the surface to $\sim 6 \mathrm{~km}$ (Fig. 6(c)) at the later stages of the system. Again, we find that the terms on the right-hand side of (1) tend to offset each other, so that the net tendency is a small residual of these terms. In the westerly onset case, the system-wide downward transport of mid-level easterlies does not take place until an organized pattern of mesoscale descent is present in a stratiform region. Although the model's reflectivity pattern at $4-5 \mathrm{~h}$ becomes somewhat disorganized, indicating the decaying character of the system, the horizontal cross-section of the VA field in Fig. 12, taken at an altitude of $2.5 \mathrm{~km}$, shows a highly organized pattern. The VA forcing in the boxed region results from weak downward velocities typical of stratiform precipitation regions. The spatial extent of the region covered by downward velocities of at least $0.25 \mathrm{~m} \mathrm{~s}^{-1}$ is about $6300 \mathrm{~km}^{2}$. This large area of mesoscale descent provides the means of transporting significant easterly momentum, either environmental or systemgenerated, toward the surface. The horizontal map of VA in Fig. 12 indicates that the large region of mesoscale descent coupled with the large-scale zonal momentum field may contribute to the negative values of $u^{\prime}$ near the surface late in the simulation.

In its later stages, the MCS establishes a significant region of easterly perturbation momentum at low levels. Figure 13(a) shows that the VA term produces a $+/-/+$ pattern in the vertical between $x=50$ and $150 \mathrm{~km}$. The VA forcing below the jet maximum $(z=5.5 \mathrm{~km})$ is strongly negative in the region where low-level easterlies are increasing near the surface. Because the low-level westerlies in the environment are at a maximum between 1 and $2 \mathrm{~km}$ rather than at the surface, the VA term is positive between the surface and the westerly maximum. Mapes and $\mathrm{Wu}$ (2001) also show regions of positive $u^{\prime}$ tendency at low levels during the westerly onset phase (e.g. their Fig. 3(c)), which increase in magnitude as the MJO transitions to its strong westerly 

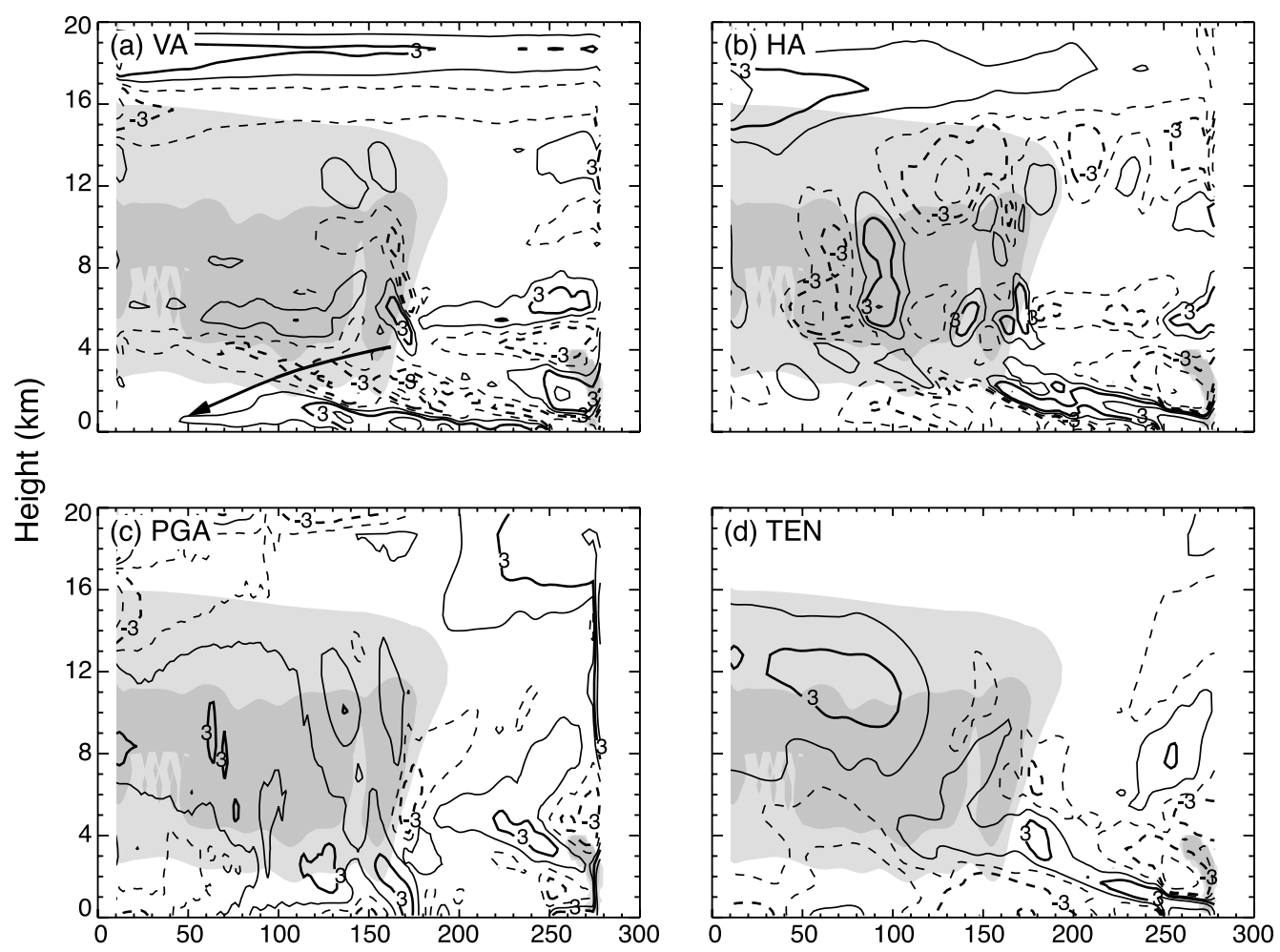

$\mathrm{X}(\mathrm{km})$

Figure 13. Vertical cross-sections of 30-minute time-mean $(5-5.5 \mathrm{~h})$ momentum forcing terms for the 14 December 1992 simulation, averaged over a strip from $y=120-160 \mathrm{~km}$ (shown in Fig. 11(a) to (d)) overlaid on the shaded total hydrometeor field (levels of $10^{-5}, 10^{-4}, 10^{-3} \mathrm{~kg} \mathrm{~kg}^{-1}$ ): (a) Vertical advection VA; (b) horizontal advection HA; (c) pressure gradient acceleration PGA; (d) momentum tendency TEN. Contour values and units are as in Fig. 10. An arrow indicating perturbation flow is superimposed over the forcings in (a).

phase. In contrast to the strong westerly simulation, where the transition from mesoscale downdraught to mesoscale updraught results in a switch in the sign of the VA term with height, here the stratiform region is less organized, and the ascent is weaker relative to the downdraught over the period in which the forcings were calculated. In addition, the weak stratiform updraught is superimposed on a region of rather weak shear, further explaining the negligible VA signal there. In contrast to the complicated $+/-/+$ VA signal in the strong westerly situation, the mesoscale downdraught acting alone on an easterly jet structure in the 14 December onset case produces a simple $-/+$ dipole, as seen on either side of the easterly jet ( $\sim .5 \mathrm{~km}$ altitude) in Fig. 13(a). This dipole is the most coherent signal of all the forcing terms, and results in an enhancement of mid- and low-level easterly momentum, except just below the low-level westerly maximum. As in the strong westerly case, the HA pattern below the easterly jet maximum $(5.5 \mathrm{~km})$ tends to be out of phase with the VA term.

\section{(c) MCS feedback in the westerly onset region}

The net tendency, TEN, arising from the combination of the processes shown in Fig. 13 is easterly in a broad region at low- and mid-levels, primarily over the western half of the domain, in association with the stratiform precipitation region 
(especially below the $2 \mathrm{~km}$ level, at $X=\sim 50-200 \mathrm{~km}$ in Fig. 13(d)). This tendency field is consistent with the profile in Fig. 6(a), which shows the development of easterly perturbation winds at low levels. The stratiform region of the MCS thus produces a negative feedback to the large-scale low-level flow, which is in the process of transitioning to a westerly regime. The terms on the right-hand side of (2) give insight into the tendency for the MCS to produce these easterly perturbation velocities at low levels. Figure 13 suggests that the negative sign of TEN in this region at heights $<2 \mathrm{~km}$ is a sequential combination of the terms on the right-hand side of (2). First, PGA accelerates mid-level flow westward as it enters the front of the system $(X=\sim 175$, height $=4-5 \mathrm{~km}$ in Fig. 13(c)); VA then transports the easterly momentum downward from mid-levels ( $X=100-200 \mathrm{~km}$, height $=1-5 \mathrm{~km}$ in Fig. 13(a)); finally HA distributes the easterly perturbation below the $2 \mathrm{~km}$ level, with help from the PGA associated with the MCS mesohigh $(X=70-15 \mathrm{~km}$, height $<2 \mathrm{~km}$ in Figs. 13(b) and (c)).

\section{EFFECT OF STRATIFORM REGION MOMENTUM TRANSPORTS ON THE LARGE-SCALE} MOMENTUM BUDGET

Houze et al. (2000) postulated that the descending westerly MCS inflows act as a positive feedback to increase low-level westerlies in the strong westerly regime of the large-scale KR wave pattern that defined the environment in TOGA COARE. They also suggested that the easterly MCS inflows at low levels acted as a negative feedback on the large-scale propagating KR wave pattern in the westerly onset phase of the KR pattern. The simulation results in section 5 are consistent with these hypothesized scenarios in showing downward transport of westerly (easterly) momentum in the stratiform region of an individual MCS of the type that occurred in the strong westerly (westerly onset) regime. The question arises: do these downward transports of easterly momentum in the stratiform regions of large MCSs have a measurable impact on the large-scale circulation in which the MCSs are embedded?

The product $w^{\prime} u^{\prime}$ (momentum flux) displayed in the boxed regions of Fig. 14 synopsizes the effect that the stratiform region and overall mesoscale organization might have on the large-scale flow. The broad zones of predominantly negative $w^{\prime} u^{\prime}$ in Figs. 14(a) and (b) over the stratiform regions in both southern and northern subdomains indicate large areas of increasing westerly momentum during the strong westerly phase. The positive region of $w^{\prime} u^{\prime}$ outlined in Fig. 14(c) indicates downward transport of easterly momentum. An area of negative $w^{\prime} u^{\prime}$ to the south of the boxed region in Fig. 14(c) results from upward transport of convectively generated easterly inflow, evident the hour before in the vertical momentum cross-section at $4 \mathrm{~h}$ in Fig. 14(d). This figure illustrates that the net vertical momentum transport in these simulations is largely dependent upon the degree of stratiform region development in the MCSs. MCSs are able to generate significant momentum, which can then be transported, along with the momentum of the large-scale environment upward and downward by the expansive regions of mesoscale vertical motions associated with the stratiform area.

Figures 15 and 16 show the domain-mean profiles of momentum flux $w^{\prime} u^{\prime}$ and vertical flux convergence, $F_{u}=-\partial w^{\prime} u^{\prime} / \partial z$, for the strong westerly simulation. The means are calculated over the entire domains (excluding the boundary-condition regions) in Figs. 4 and 5, and over individual stratiform regions. Mean fluxes and convergences taken over the entire domains likely contain contributions from the imposed boundary conditions and thus do not perfectly represent the TEN contribution from the MCSs on the large scale. More properly, the means should be interpreted qualitatively as described 
(a) 23-24 Dec. 1992 (Southern subdomain)

(b) 23-24 Dec. 1992 (Northern subdomain)
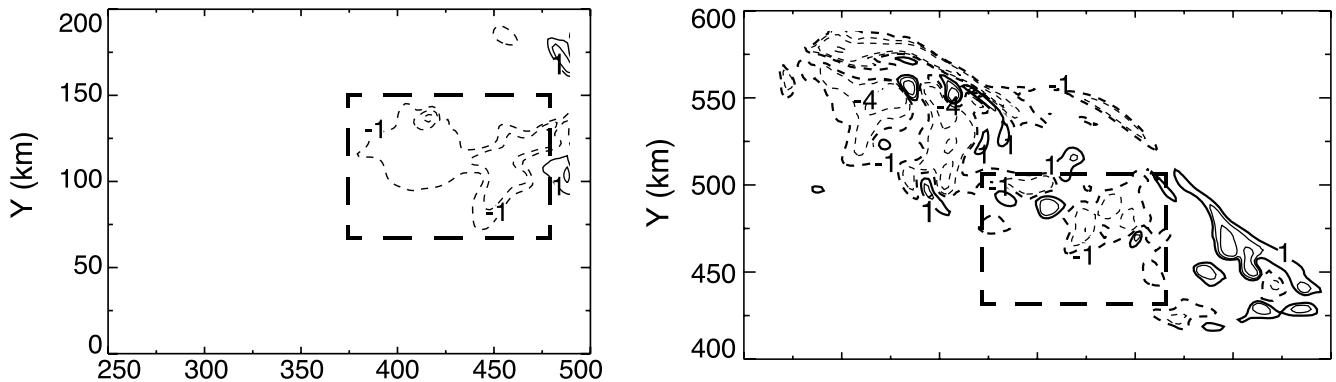

(c) 14 Dec. 1992

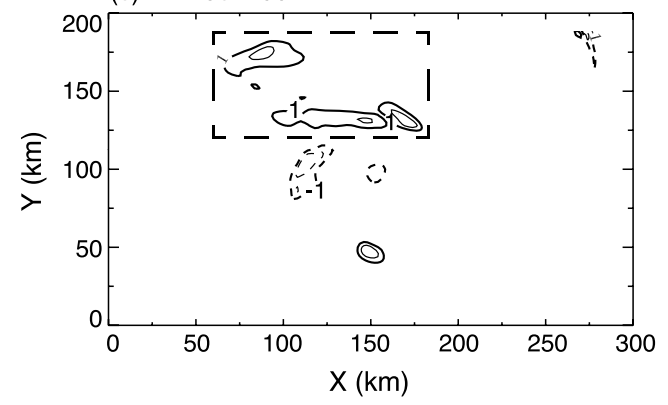

Figure 14. Horizontal cross-sections of $w^{\prime} u^{\prime}$ (see text) for: (a) the 23-24 December 1992 simulation, at a height of $1 \mathrm{~km}$ at $5 \mathrm{~h}$, over the southern subdomain; (b) as (a) but over the northern subdomain; (c) the 14 December 1992 simulation, taken at a height of $2.5 \mathrm{~km}$ at $5.5 \mathrm{~h}$. Contour values are $-16,-4,-2,-11,2,4,16 \mathrm{~m}^{2} \mathrm{~s}^{-2}$. Boxes bound regions of $w^{\prime} u^{\prime}$, negative in (a) and (b) and positive in (c), which are thought to be characteristic for each flow regime.

(a) Whole domain

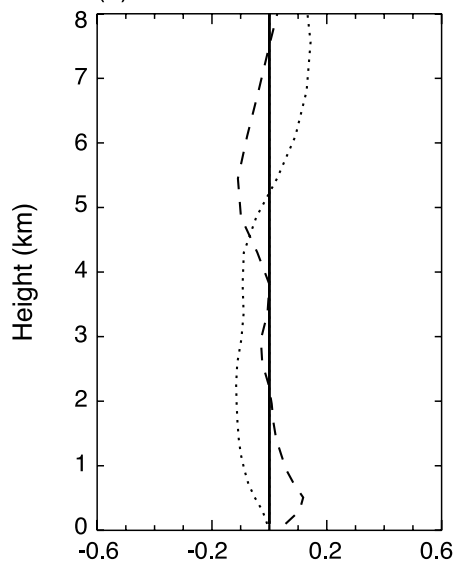

(b) Southern stratiform

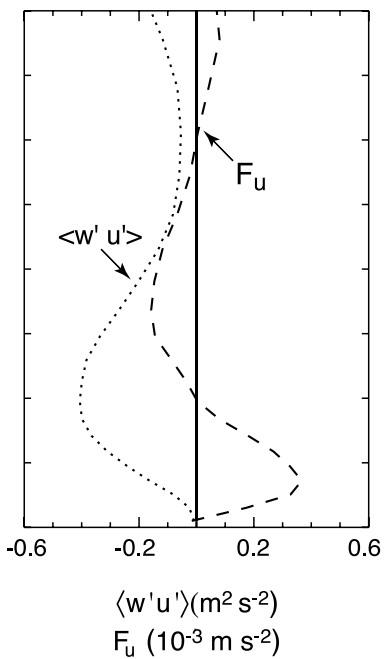

(c) Northern stratiform

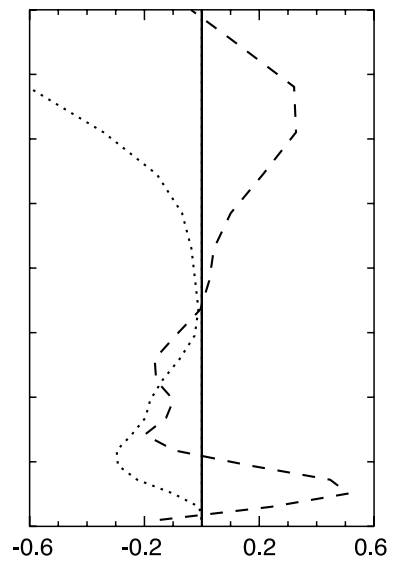

Figure 15. Vertical profiles of $\left\langle w^{\prime} u^{\prime}\right\rangle$ and $F_{u}=-(\partial / \partial z)\left\langle w^{\prime} u^{\prime}\right\rangle$ for the 23-24 December 1992 simulation at $5 \mathrm{~h}$. Averages are taken over (a) the whole domain, (b) the southern stratiform domain, and (c) the northern stratiform domain. Stratiform regions are denoted by dashed boxes in Fig. 5(f). See text for further details. 
(a) Whole domain

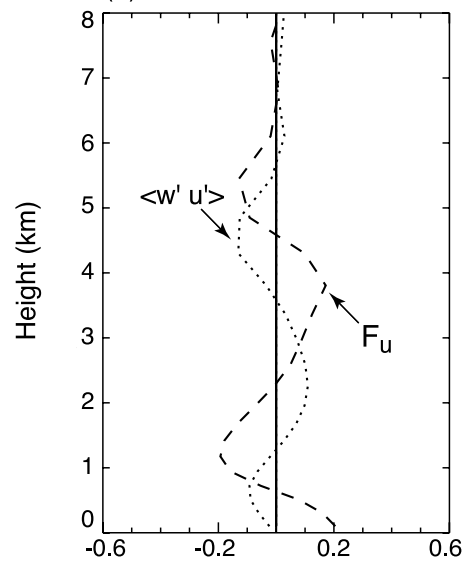

(b) Stratiform

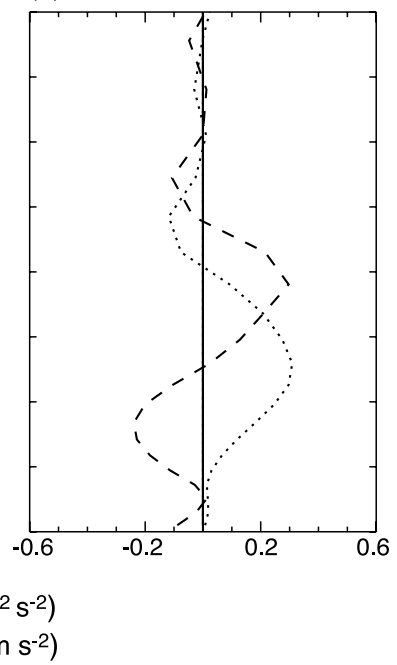

Figure 16. Vertical profiles of $\left\langle w^{\prime} u^{\prime}\right\rangle$ and $F_{u}=-(\partial / \partial z)\left\langle w^{\prime} u^{\prime}\right\rangle$ for the 14 December 1992 simulation at $5.5 \mathrm{~h}$. Averages are taken over: (a) the whole domain, and (b) the stratiform domain. The stratiform region is similar to the region enclosed by the box in Fig. 4(h). See text for further details.

in section 2, namely that they convincingly imply feedback on the large-scale momentum and KR wave structures. The strong westerly case illustrated in Fig. 15 shows that the southern stratiform region has a deep layer of negative $w^{\prime} u^{\prime}$ and a layer from $0-2 \mathrm{~km}$ of increasing westerlies with time. The northern stratiform region exhibits a similar behaviour, though the layers of $w^{\prime} u^{\prime}$ and $F_{u}$ are somewhat shallower. The terms $w^{\prime} u^{\prime}$ and $F_{u}$ averaged over the entire domain indicate the same signal, though of course weaker, with negative $w^{\prime} u^{\prime}$ throughout the layer below the melting level and positive momentum tendencies from the surface to $2 \mathrm{~km}$. Figure 16 shows that the stratiform contribution is also important in the westerly onset phase, with the deep layer of positive $w^{\prime} u^{\prime}$ over the stratiform region in Fig. 16(b) reflected in the whole-domain mean (Fig. 16(a)). These mean profiles demonstrate that the stratiform regions had an appreciable impact on the domain-mean momentum tendencies, and that convection in its decaying stages substantially influenced the overall large-scale momentum budget.

\section{CONCLUSIONS}

The cloud-resolving model simulations in this study demonstrate the importance of the mesoscale circulations associated with stratiform regions of large MCSs on the momentum budget of the large-scale flow over the tropical Pacific warm pool. When MCSs become large, as they often do over the warm pool (Nakazawa 1988; Mapes and Houze 1993; Chen et al. 1996) downward momentum transport in the stratiform regions is robust. The domain-averaged profiles of $w^{\prime} u^{\prime}$ (Figs. 15 and 16) illustrate that the broad regions of stratiform precipitation have a measurable impact on the MCSmean budget. This behaviour is consistent with the conclusions of Moncrieff and Klinker (1997) that the 'superclusters' (i.e. groups of MCSs with larger stratiform regions) can have a significant impact on the large-scale momentum budget over the warm pool.

The dynamics of warm-pool MCSs is quite complex, with momentum transport signals that can be quite different from convective to stratiform region. The manner in 
which warm-pool convection affects the large-scale momentum fields is dependent on the large-scale flow, which tends to be a function of the phase of the MJO. This study confirms the suggestion of Houze et al. (2000) that the momentum transport character of the convection is dependent upon the phase of the KR wave structure and the degree of stratiform region development attained by the MCSs. Houze et al. (2000) suggested that the warm-pool convection can be thought of as a feedback effect on the amplitude and propagation of the large-scale KR wave pattern. In this study we carried out simulations that emphasize how the stratiform-region circulations of large MCSs may influence the establishment and maintenance of strong low-level westerlies as the MJO progresses.

In the strong westerly phase, the mesoscale downward air motion in the stratiform regions of MCSs transports westerly momentum downward, thus further strengthening the low-level westerlies and hence constituting a positive feedback on the KR wave structure, via direct enhancement of the momentum field as well as via convective and surface-flux feedbacks. In the westerly onset phase the mesoscale descent in the stratiform regions of MCSs appears to act as a negative feedback on the propagation of the wave pattern, depending upon the partitioning of momentum forcing between convective and stratiform portions of the MCS. PGAs associated with the tilted updraught/downdraught structure tended to increase the mean shear at low and middle levels, and in the stratiform region, the accelerating mid-level easterly momentum was advected down to low levels by the sloping mesoscale stratiform-region downdraught, thus acting to counter the low-level westerlies which the propagating wave pattern was attempting to establish. These results confirm the downward transport signal previously documented in Doppler radar data in the stratiform regions of warm-pool MCSs in TOGA COARE (Houze et al. 2000).

\section{ACKNOWLEDGEMENTS}

We thank Chris Bretherton and Carl Hane for valuable comments on the research and Peter Lamb for support and encouragement to finish the project. Interaction with Mitch Moncrieff and suggestions by an anonymous reviewer greatly improved the presentation of the manuscript. Ming Xue assisted with the ARPS model. Candace Gudmundson edited the manuscript, and Kay Dewar and Beth Tully refined the figures. This research was supported by the Office of Naval Research grant N00014-01-10156, the National Science Foundation grants ATM9409988 and ATM9908944, and the National Oceanic and Atmospheric Administration grant numbers NA67RJ0155 (CIMAS/UM) and NA17RJ1232 (JISAO contribution number 1095). The lead author was supported during the course of this investigation by the Environmental Sciences Division of the US Department of Energy (through Battelle PNR Contract 144880-AQ1 to the Cooperative Institute for Mesoscale Meteorological Studies) as part of the Atmospheric Radiation Measurement Program and the Office of Naval Research grant N00014-03-1-0304.

\section{REFERENCES}

Braun, S. A. and Houze, R. A. Jr.

Bryan, G. H. and Fritsch, J. M.

Chen, S. S.
1997

2000

1997

The evolution of the 10-11 June 1985 PRE-STORM squall line: Initiation, development of rear inflow, and dissipation. Mon. Weather Rev., 125, 478-504

Moist absolute instability: The sixth static stability state. Bull. Am. Meteorol. Soc., 81, 1207-1230

'Convectively active and suppressed periods in TOGA COARE'. Pp. 583-586 in Pre-prints of the 22nd Conference on hurricanes and tropical meteorology, Ft. Collins, CO. American Meteorological Society, Boston, USA 
Chen, S. S. and Houze, R. A. Jr.

Chen, S. S., Houze, R. A. Jr. and Mapes, B. E.

Davies, $\mathrm{H}$.

Gill, A.

Godfrey, J. S., Houze, R. A. Jr., Johnson, R. H., Lukas, R., Redelsperger, J.-L., Sumi, A. and Weller, R.

Grell, G., Dudhia, J. and Stauffer, D. R.

Houze, R. A. Jr.

Houze, R. A. Jr., Rutledge, S. A., Biggerstaff, M. I. and Smull, B. F.

Houze, R. A. Jr., Chen, S. S., Kingsmill, D. E., Serra, Y. and Yuter, S. E.

Kain, J. S. and Fritsch, J. M.

Kingsmill, D. E. and

Houze, R. A. Jr.

LeMone, M. A.

Lin, X. and Johnson, R. H.

Lin, Y.-L., Farley, R. D. and Orville, H. D.

Madden, R. and Julian, P.

Mapes, B. E. and Houze, R. A. Jr.

Mapes, B. E. and Wu, X.

Mechem, D. B., Houze, R. A. Jr. and Chen, S. S.

Moncrieff, M. W.
1982

1989

1993

1997 Stratiform precipitation in regions of convection: A meteorological paradox? Bull. Am. Meteorol. Soc., 78, 2179-2196

2004 Mesoscale convective systems. Rev. Geophys., 10.1029/2004RG000150

1983

2000

1990

1999

1996

1983

1971

1972

1993

2001

nal variations and life-cycle of deep convective systems over the tropical Pacific warm pool. Q. J. R. Meteorol. Soc., 123, 357-388

Interannual variability of deep convection over the tropical warm pool. J. Geophys. Res., 102, 25783-25795

Multiscale variability of deep convection in relation to large-scale circulation in TOGA COARE. J. Atmos. Sci., 53, 1380-1409

Limitations of some common lateral boundary schemes used in regional NWP models. Mon. Weather Rev., 111, 1002-1012

Some simple solutions for heat-induced tropical circulation. Q. J. R. Meteorol. Soc., 106, 447-462

COARE: An interim report. J. Geophys. Res., 103, 7, 1439514450

'A description of the fifth-generation Penn State/NCAR mesoscale model (MM5)'. NCAR Technical Note NCAR/TN398+STR. The National Center for Atmospheric Research, Boulder CO, USA

A climatological study of vertical transports by cumulus-scale convection. J. Atmos. Sci., 30, 1112-1123

Cloud clusters and large-scale vertical motions in the tropics. J. Meteorol. Soc. Jpn, 60, 396-410

Observed structure of mesoscale convective systems and implications for large-scale heating. Q. J. R. Meteorol. Soc., 115, 425-461

Cloud dynamics. Academic Press, San Diego, USA

Interpretation of Doppler weather radar displays in midlatitude mesoscale convective systems. Bull. Am. Meteorol. Soc., 70, 609-619

Convection over the Pacific warm pool in relation to the atmospheric Kelvin-Rossby wave. J. Atmos. Sci., 57, 3058-3089

A one-dimensional entraining/detraining plume model and its application in convective parametrization. J. Atmos. Sci., 47, 2784-2802

Kinematic characteristics of air flowing into and out of precipitating convection over the west Pacific warm pool: An airborne Doppler radar survey. Q. J. R. Meteorol. Soc., 125, 11651207

Momentum transport by a line of cumulonimbus. J. Atmos. Sci., 40, 1815-1834

Kinematic and thermodynamic characteristics of flow over the western Pacific warm pool during TOGA COARE. J. Atmos. Sci., 53, 695-715

Bulk parametrization of the snow field in a cloud model. J. Clim. Appl. Meteorol., 22, 1065-1092

Detection of a 40-50 day oscillation in the zonal wind in the tropical Pacific. J. Atmos. Sci., 28, 702-708

Description of global scale circulation cells in the Tropics with a 40-50-day period. J. Atmos. Sci., 29, 1109-1123

Cloud clusters and superclusters over the oceanic warm pool. Mon. Weather Rev., 121, 1398-1415

Convective eddy momentum tendencies in a long cloud-resolving model simulation. J. Atmos. Sci., 58, 517-526

2002 Layer inflow into precipitating convection over the western tropical Pacific. Q. J. R. Meteorol. Soc., 128, 1997-2030

1978 The dynamical structure of two-dimensional steady convection in constant vertical shear. Q. J. R. Meteorol. Soc., 104, 543-568

1981 A theory of organised steady convection and its transport properties. Q. J. R. Meteorol. Soc., 107, 29-50 
Moncrieff, M. W.

1992 Organized convective systems: Archetypal dynamical models, mass and momentum flux theory, and parametrization. Q. J. R. Meteorol. Soc., 118, 819-850

2004 Analytic representation of the large-scale organization of tropical

convection. J. Atmos. Sci., 61, 1521-1538
Organized convective systems in the tropical western Pacific as

Moncrieff, M. W. and Klinker, E.

Moncrieff, M. W. and Miller, M. J. 1976

Nakazawa, T.

Potter, B. E.

Rotunno, R., Klemp, J. B. and Weisman, M. L.

Schneider, E. K. and Lindzen, R. S. 1976

Shapiro, L. J. and Stevens, D. E. 1980

Smull, B. F. and Houze, R. A. Jr.

Trier, S. B., LeMone, M. A. and Skamarock, W. C.

Tung, W.-W. and Yanai, M.

Xue, M., Droegemeier, K. K., Wong, V., Shapiro, A. and Brewster, K.

Yang, M.-J. and Houze, R. A. Jr.

Zipser, E. J.
1997

1988

1991

1987 a process in general circulation models: A TOGA COARE case-study. Q. J. R. Meteorol. Soc., 123, 805-827

The dynamics of simulation of tropical squall-lines. $Q$. J. $R$. Meteorol. Soc., 102, 373-394

Tropical super clusters within intraseasonal variations over the western Pacific. J. Meteorol. Soc. Jpn, 66, 823-839

Improvements to a commonly used cloud microphysical bulk parametrization. J. Appl. Meteorol., 30, 1040-1042

1988 A theory for strong, long-lived squall lines. J. Atmos. Sci., 45, $463-485$

A discussion of the parametrization of momentum exchange by cumulus convection. J. Geophys. Res., 81, 3158-3160

Parametrization of convective effects on the momentum and vorticity budgets of synoptic-scale Atlantic tropical waves. Mon. Weather Rev., 108, 1816-1826

Rear inflow in squall lines with trailing stratiform precipitation. Mon. Weather Rev., 115, 2869-2889

1998 Effect of three-dimensional structure on the stormwide horizontal accelerations and momentum budget of a simulated squall line. Mon. Weather Rev., 126, 2580-2598

2002 Convective momentum transport observed during the TOGA COARE IOP. II: Case studies. J. Atmos. Sci., 59, 2535-2549

1995 'ARPS Version 4.0 User's Guide'. Center for the Analysis and Prediction of Storms, University of Oklahoma, USA

1995a Multicell squall-line structure as a manifestation of vertically trapped gravity waves. Mon. Weather Rev., 123, 641-661

$1995 \mathrm{~b}$ Sensitivity of squall-line rear inflow to ice microphysics and environmental humidity. Mon. Weather Rev., 123, 31753193

1996 Momentum budget of a squall line with trailing stratiform precipitation: Calculations with a high-resolution numerical model. J. Atmos. Sci., 53, 3629-3652

1969 The role of organized unsaturated convective downdrafts in the structure and rapid decay of an equatorial disturbance. J. Appl. Meteorol., 8, 799-814

1977 Mesoscale and convective-scale downdrafts as distinct components of squall-line circulation. Mon. Weather Rev., 105, 1568-1589 